\title{
Kinetics and mechanism of acid catalyzed alkylation of phenol with cyclohexene in the presence of styrene divinylbenzene sulfonic resins
}

\author{
L. Ronchin*, G. Quartarone, A. Vavasori \\ Department of Molecular Science and Nanosystems, University Ca' Foscari of Venice, Dorsoduro 2137, 30123 Venice, Italy
}

\section{A R T I C L E I N F O}

\section{Article history:}

Received 11 September 2011

Received in revised form

24 November 2011

Accepted 25 November 2011

Available online 6 December 2011

\section{Keywords:}

Acid catalysis

Sulfonated resins

Phenol alkylation

Alkylation mechanism

Alkylation kinetics

\begin{abstract}
A B S T R A C T
The kinetics of phenol cyclohexylation catalyzed by sulfonic resins is studied taking into account equilibria and side reactions observed in the reaction media. The influence of different sulfonic resins has been tested and only small variation of the catalyst activity, referred to the acid amount, has been observed. Besides, the selectivity is unaffected by varying the type of the catalyst. The effect of reagent concentration on the reaction rate has been also studied, together with the reactivity of the cyclohexyl phenyl ether as intermediate. The etherification equilibrium of cyclohexyl phenyl ether has been analyzed in the presence of methanesulfonic acid, and the adsorption equilibria on a sulfonic resin of reagents and intermediates are measured, too. Starting from the evidences obtained from these studies an Eley-Rideal type kinetic model has been proposed and the fitting of the experimental data allows obtaining the kinetic constant of each stage. Good reliability of the model with the experimental data has been observed, also at high conversion, and the values of the fitting parameters are substantially constant by varying the operative variable, which is a further proof of the goodness of the model.
\end{abstract}

(C) 2011 Published by Elsevier B.V.

\section{Introduction}

Alkylphenols and alkyl phenyl ethers are molecules of considerable interest because of their industrial relevance [1-3]. As a matter of fact, the world production of alkylphenols exceeds 460,000 t/yr. The vast majority of alkylphenols is used to synthesize derivatives which have applications ranging from surfactants to pharmaceuticals. In additions, the use of alkylphenols in the production of both polymer additives and monomers for engineering plastics is expected to show a constant growth during the next years. Alkyl phenyl ethers are compounds of great interest in the field of fine chemicals and their production is in continuous expansion especially in the new markets [1-3].

The cation-exchange resins are used as catalysts in a large number of industrial processes, such as the manufacture of alkyl phenols, the esterification of carboxylic acids, the synthesis of ethers, the hydration of alkenes, etc. [4-9]. The use of these heterogeneous systems is a suitable alternative to the usual procedures in a homogeneous system in the presence of mineral acids and ionexchange resins appear to be ideal catalysts to convert polluting processes into greener ones [4-12].

Phenol is an activated molecule to the electrophilic aromatic substitutions and its mechanism of alkylation has been known for

\footnotetext{
* Corresponding author. Fax: +39 0412348517

E-mail address: ronchin@unive.it (L. Ronchin).
}

a long time $[1,3,13-15]$. Some aspects, connected to kinetics and selectivity of phenol cyclohexylation, however, are not completely elucidated. In particular, the studies of Sharma and coworkers carried out in the early nineties, relative to the reactivity of several olefins toward phenol in the presence of sulfonated resins, pointed out that the ortho-para selectivity in the ring alkylation of phenol is strictly related to the nature of the olefin. In particular, propene and 1-butene give an ortho-para ratio close to 2, while isobutene, $\alpha$-methyl styrene and diisobutene give almost exclusively para alkylation [16]. More recently, Hölderich and coworkers showed that high para selectivity is obtained in the alkylation of phenol with isobutene and the nature of the acid catalysts does not influence the selectivity. On the contrary, catalyst activity is influenced by the amount and the strength of the acid sites [17]. In these studies there are no evidences of cyclohexylphenyl ether formation; in contrast, by using cyclohexene as alkylating agent, the formation of the ether occurs with high yield by using solid acid catalysts with different nature [18-20]. For instance, Yadav and Kumar have recently studied the kinetics of phenol cyclohexylation catalyzed by many solid acids in solvent-less conditions at $333 \mathrm{~K}$ [18]. The time concentrations profile shows the formation of cyclohexyl phenyl ether, as the most abundant product (70\%) after $4 \mathrm{~h}$ of reaction. Ring alkylation occurs in lesser extent and the ortho-para ratio is in the range 2-7 depending on the type of the catalyst used [18]. In that work the best fit of the data are obtained by an Eley-Rideal kinetic model, but several aspects of the kinetics were not studied. More recently, Yadav and Pathre studied the cyclohexylation of guaiacol 
catalyzed by several solid catalysts. Also in this work, the formation of the ether is observed but its concentration passes through a maximum and finally decreases to complete consumption [21,22]. Also in this case the best fit of the data was obtained by an Eley-Rideal kinetic model, but a consecutive rearrangement of the ether was implemented in the model thus explaining its disappearance [21]. Quite surprisingly, there is no mention of the etherification equilibrium, which is well known for aliphatic ether, and it is evident also for the cyclohexylphenyl ether [23,24].

The mechanistic aspect of the electrophilic attack to the phenol is investigated from a theoretical point of view with DFT studies by Tang and coworkers. These authors suggested that an olefin reacts with a sulfonic acid leading to the formation of a sulfonic ester intermediate, which, in turns, reacts with phenol to form the products of alkylation [25].

In this paper we study the kinetics of phenols cyclohexylation catalyzed by some sulfonic resins in order to highlight some unclear aspects of this reaction. In particular we try to develop a kinetic model taking into account the different equilibria, since both the cyclohexylphenyl ether and heterogeneous equilibria affect the overall kinetics. In addition, the reactivity of the cyclohexyl phenyl ether, recognized as a transient intermediate, is implemented in the model [24].

\section{Experimental}

\subsection{Materials}

Reagents and solvents were used after purification of the commercially available samples and their purity was checked by melting point, thin layer chromatography (TLC), high performance liquid chromatography (HPLC), gas chromatography (GC) and gas chromatography coupled to a mass spectroscopy (GC-MS). The solvents were treated in a double bed column, filled with $\mathrm{H}_{2} \mathrm{SO}_{4} / \mathrm{SiO}_{2}$ and $\mathrm{SiO}_{2}$ to adsorb water and impurities. The residual water content was checked by HPLC analysis and its concentration is in the range of $10-20 \mathrm{ppm}$ [26]. Commercial catalysts: macro-reticular sulfonated styrene divinyl benzene resins Amberlyst 15 and Amberlyst 36, which are a trade mark of Rohm and Haas, were purchased from Aldrich. Deuterated chloroform for NMR measurements was purchased from Euriso-Top.

\subsection{Catalysts preparation}

Amberlyst $15-\mathrm{NO}_{2}$ and Amberlyst $36-\mathrm{NO}_{2}$ nitrated resins were prepared as follows. In a typical preparation $5 \mathrm{~g}$ of styrene divinyl benzene sulfonated resin was dispersed in $50 \mathrm{~mL}$ of $\mathrm{H}_{2} \mathrm{SO}_{4}$ (95-98 wt.\%) and thermostatted at $273 \mathrm{~K}$. The nitrating mixture was prepared by diluting $40 \mathrm{mmol}$ of $\mathrm{HNO}_{3}$ (65 wt.\%) in $50 \mathrm{~mL}$ of $\mathrm{H}_{2} \mathrm{SO}_{4}$ (95-98 wt.\%). The solution was thermostatted and added drop wise to the resin suspended in the sulfuric acid and left under gently agitation for the time of treatment (1-3 h). Subsequently, the solid was filtered and washed with plenty water, whose $\mathrm{pH}$ was continuously checked until the neutrality was reached in order to minimize the acid adsorbed. The catalyst was finally desiccated at $373 \mathrm{~K}$ for $72 \mathrm{~h}$ under nitrogen flow. Sulfonation on the commercial sulfonated resins (Amberlyst $15-\mathrm{SO}_{3}$ and Amberlyst $36-\mathrm{SO}_{3}$ ) was carried out by the same procedure described above but in the presence of neat $\mathrm{H}_{2} \mathrm{SO}_{4}$ (98 wt.\%) at $298 \mathrm{~K}$ for $2 \mathrm{~h}$.

\subsection{Catalysts characterization}

The total ions exchange capacity (TIEC) of the solids was determined by potentiometric back titration with $\mathrm{HCl}$ of standard solutions of $\mathrm{NaOH}$ after adsorption of the base on the resins.
Brunauer-Emmet-Teller surface area, pore size distribution (obtained by Barrett-Joyner-Halenda model) and total pore volume (measured at $p / p_{0}=0.98$ of relative pressure) of the catalysts have been determined by $\mathrm{N}_{2}$ adsorption and desorption at $94 \mathrm{~K}$ using an automatic adsorption unit (Micromeritics ASAP 2010C) [27].

The infrared spectroscopy measurement (IR) was carried out on the solid resin and the sample was prepared as follows: a small amount of resin (c.a. $10 \mathrm{mg}$ ) is grinded in an agate mortar with $\mathrm{KBr}$ (c.a. $1 \mathrm{~g}$ ). The resulting fine powder was pressed at $1000 \mathrm{Mpa}$ for 5 min, and the disk was loaded on a Perkin Elmer spectrum 65 FTIR at $2 \mathrm{~cm}^{-1}$ of resolution.

Elemental analysis of the Amberlyst $15-\mathrm{NO}_{2}$ catalyst has been carried out in a PerkinElmer 2400 Series II CHN elemental Analyzer.

\subsection{Reactions}

The reactions were performed in a well stirred baffled glass reactor (generally at $12 \mathrm{~Hz}$ of stirring speed by using a Rushtone turbine) thermostatted by circulation bath in the range $288-373 \mathrm{~K}$, containing weighed samples of solvent, reagents and catalyst at autogenous solvent pressure (i.e. $122 \mathrm{kPa}$ for 1,2-dichloroethane at $358 \mathrm{~K}$ ). In a typical experiment $10 \mathrm{~mL}$ of solution containing $10 \mathrm{mmol}$ of phenol, $10 \mathrm{mmol}$ of cyclohexene plus $5 \mathrm{mmol}$ of methylcyclohexane as internal standard and the desired amount of catalyst (100-500 mg) were placed into the reactor. All the operations were carried out inside a glove box in order to minimize catalyst deactivation by air moisture. Small amounts of the solution were drawn at different times and the samples were analyzed by GC(Agilent 7890) and GC-MS (Agilent 7890+), using a HP5 capillary column (300 $\mu \mathrm{m}$ i.d. $30 \mathrm{~m}$ long, $95 \%$ methyl, $5 \%$ phenyl silicone phase). The samples were checked also by HPLC using a Perkin Elmer 250 equipped with a diode array LC-235 detector and a Lichrosphere $100(\mathrm{RP}-18,5 \mu \mathrm{m})$ column.

For a reliable comparison of the performances of different catalysts it is essential to know if the reaction rate data are affected by diffusion phenomena. This is verified by studying the influence of the speed of agitation, the granulometry and the catalyst amount on the reaction rate catalyzed by the most active catalyst at the highest temperature of reactions (Amberlyst 36 as catalyst at $368 \mathrm{~K}$ ). The experimental evidences suggest that the kinetics is not influenced by diffusion phenomena since there are no differences in the initial reaction rate when the agitation speed vary from 10 to $16 \mathrm{~Hz}$. In addition, the initial reaction rates are strictly proportional to the catalyst amount by using resins with different granulometry. Furthermore, the inspection of Carberry and Wheeler-Weisz numbers shows values of 0.08 and 0.35 , respectively, thus suggesting a negligible influence of the diffusion phenomena on the rate of reaction $[28,29]$.

The initial reaction rate is calculated by the first derivative at time zero of the function obtained by the regression of cyclohexene consumption data with a third order polynomial. In this way, we calculate the apparent activation energy (AAE) by the slope of the Arrhenius plot obtained from the initial rate of reaction at different temperatures [24].

\subsection{NMR measurements}

${ }^{13} \mathrm{C}$ proton decoupled nuclear magnetic resonance spectra (NMR) were recorded at $75 \mathrm{MHz}$ at $243 \mathrm{~K}$ with a Bruker Avance 300 spectrometer. NMR chemical shifts are internally referred to the solvent resonance and are quoted relative to internal tetramethylsilane $(\delta=0 \mathrm{ppm})$. All the measurements were carried out in tubes sealed by a screw cap in order to add known amounts of methanesulfonic by a micro syringe. In a typical experiment $0.6 \mathrm{mmol}$ of phenol, cyclohexene or cyclohexyl phenyl ether were added to 
$0.6 \mathrm{~mL}$ of $\mathrm{CDCl}_{3}$ and, after standard measurements, incremental amounts of $\mathrm{CH}_{3} \mathrm{SO}_{3} \mathrm{H}$ were added to the NMR tube cooled to $243 \mathrm{~K}$ and transferred into the probe pre-cooled at $243 \mathrm{~K}$.

\subsection{Etherification and adsorption equilibria}

The equilibrium of etherification was studied by measuring the products of cyclohexyl phenyl ether decomposition (phenol and cyclohexene) catalyzed by methanesulfonic acid, which is a poor catalyst for ring alkylation reactions [24]. The observed equilibrium constants are measured by using the same reactor with the same reaction volume used for the reactions of alkylation, in the temperature range comprised between $348 \mathrm{~K}$ and $368 \mathrm{~K}$, in the presence of $180 \mathrm{mg}$ of methanesulfonic acid, with an initial ether concentration of c.a. $0.2 \mathrm{~mol} \mathrm{~L}^{-1}$. When the concentration of both phenol and cyclohexene reached their maxima (e.g. see Fig. 6), the preequilibrium approximation is assumed to hold [30]. Cyclohexene, phenol and cyclohexyl phenyl ether are then in thermodynamic equilibrium, thus the etherification equilibrium constant can be calculated by the concentrations of reagent and products.

The equilibrium of adsorption on the resins is evaluated by measuring the adsorption of reagents and products between $278 \mathrm{~K}$ and $298 \mathrm{~K}$ and extrapolated at the temperature of reaction. Adsorption measurements were carried out at temperatures lower than those normally employed in the reactions to maximize the amount of the adsorbate. In addition, under these conditions, product formation is suppressed. In a typical experiment $800 \mathrm{mg}$ of catalyst is placed in contact with $10 \mathrm{~mL}$ of solution at known concentration for $1 \mathrm{~h}$, in the same reactor used for alkylation reactions (stirring speed: $12 \mathrm{~Hz}$ ), and the amount of adsorbate evaluated by difference after GC analysis. Langmuir adsorption model is used to fit experimental data and the equilibrium constant was measured at low coverage at the initial slope of fractional coverage [31].

\subsection{Non linear regression analysis of the kinetic model}

The regression of the data was carried out on simultaneous algebraic-differential equations numerically evaluated at each experimental point $\left(X_{\mathrm{i}}, Y_{\mathrm{i}}\right)$. The minimization of the square residual sum was achieved by a step-descent method and the convergence was verified by reducing the step of 10 time and obtaining constant values of the square residuals sum [32,33]. The regression function $f$ depends on the kinetic constants $\left(k_{\mathrm{e}}, k_{\mathrm{o}}, k_{\mathrm{p}}, k_{\mathrm{ro}}, k_{\mathrm{rp}}, k_{\mathrm{d}}, k_{\mathrm{dcp}}\right)$, which are also the regression variables (see details in Section 3.2.5). The large number of parameters employed in the model does not allow to obtain reliable values for the whole set of kinetic constants by a direct fitting of a single set of data. For this reason the evaluation has been carried out by dividing the kinetic constants in three groups of unrelated evaluation steps, which correspond to independent experimental data. The first group of kinetic constants $\left(k_{\mathrm{e}}, k_{\mathrm{o}}, k_{\mathrm{p}}\right.$, $k_{\mathrm{dcp}}$ ) are those directly related to the consumption of the reagents and are evaluated by fitting the data of reactions of cyclohexylation of phenol employing Eq. ( 1$)$. The $\operatorname{second~group~}\left(k_{\mathrm{ro}}, k_{\mathrm{rp}}\right)$ is evaluated by fitting the profile of cylohexylphenyl ether rearrangement with Eq. (2). Finally, the evaluation of $k_{\mathrm{d}}$, the kinetic constant relative to the cyclohexene dimerization, can be simply evaluated by the slope of the cyclohexylcyclohexene formation standardized by the acid concentration, since the observed reaction order is zero in the cyclohexene concentration (see Section 3.2.4).

This procedure is possible because each set of parameters does not influence significantly the fitting of the others, in this way, the regression variables of each fitting results unrelated:

$\chi_{k 1}^{2}=\sum_{i=0}^{i=n}\left[Y_{i}-f\left(X_{\mathrm{i}}, k_{\mathrm{e}}, k_{\mathrm{o}}, k_{\mathrm{p}}, k_{\mathrm{dcp}}\right)\right]^{2}$

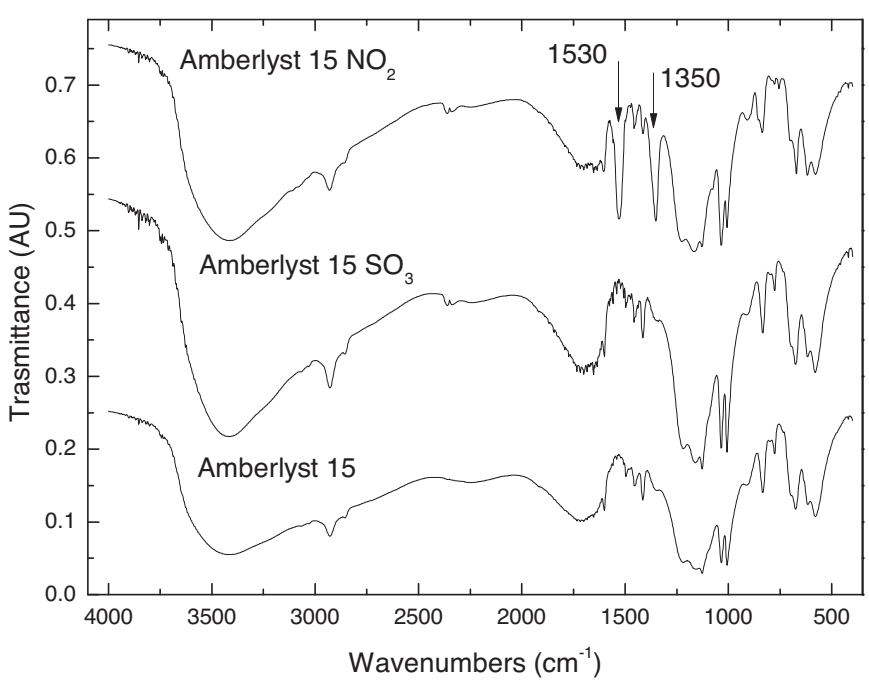

Fig. 1. Comparison of the infrared spectra of neat, sulfonated and nitrated Amberlyst 15 in $\mathrm{KBr}$.

$\chi_{k 2}^{2}=\sum_{i=0}^{i=n}\left[Y_{i}-f\left(X_{\mathrm{i}}, k_{\mathrm{ro}}, k_{\mathrm{rp}}\right)\right]^{2}$

The calculated error on the kinetic constants are in the range $10-50 \%$ because of the large number of fitting variables, and the goodness of the model is analyzed by the time sequence plot of the residuals [33].

\section{Results and discussion}

\subsection{Synthesis and characterization of catalysts}

Sulfonated styrene divinyl benzene resins (Amberlyst ${ }^{\mathrm{TM}} 15$ and 36) have been treated with nitric acid and sulfuric acid in order to obtain new acid catalysts to be tested in the alkylation of phenol with cyclohexene. Average pore diameter, pore volume, BET surface area and TIEC of the resins are summarized in Table 1. Average pore diameter (AVP) does not significantly change upon treatments. Only a moderate increase of the AVP is observed for the sulfonated Amberlyst 15 and for the nitrated Amberlyst 36. On the contrary, pore volume and surface area increase after the treatments particularly for Amberlyst 36. As expected, TIEC values slightly increase only after sulfonation, most likely due to formation of new sulfonic groups on the polymeric framework. On the contrary, nitration diminishes the TIEC probably because of the substitution of sulfonic groups with nitro groups, which cannot exchange ions [14,15]. This is in agreement with the data obtained by elemental analysis of the Amberlyst $15-\mathrm{NO}_{2}$ (Table 1 , entry 2), which corresponds to a elemental composition of $\mathrm{C}_{26} \mathrm{H}_{34} \mathrm{~N}$ that is c.a. 2 mequiv. $\mathrm{g}^{-1}$ of $\mathrm{NO}_{2}$ on the resin, by considering that nitrogen derives by the nitro group. At difference of both Amberlyst 15 and Amberlyst 15$\mathrm{SO}_{3}$, the IR spectrum of the nitrated resins show two new sharp bands at $1530 \mathrm{~cm}^{-1}$ and $1350 \mathrm{~cm}^{-1}$, assigned to asymmetric and symmetric NO stretching of the nitro group [34] (Fig. 1). Molecular nitric acid, its hydrates and nitrate ions are not detected by IR analysis in the characteristic range of frequencies $\left(1600-1700 \mathrm{~cm}^{-1}\right)$ assigned to these compounds [35]. As expected the IR spectra of the Amberlyst $15-\mathrm{SO}_{3}$ does not change significantly. The spectra relative to neat Amberlyst 36, Amberlyst $36-\mathrm{SO}_{3}$ and Amberlyst $36-\mathrm{NO}_{2}$ are reported in Fig. 2. As a matter of fact, Amberlyst 36 and Amberlyst 36- $\mathrm{SO}_{3}$ show negligible spectral differences, while Amberlyst $36-\mathrm{NO}_{2}$ shows the two sharp bands at $1530 \mathrm{~cm}^{-1}$ and $1350 \mathrm{~cm}^{-1}$ of the $\mathrm{NO}_{2}$ assigned to asymmetric and symmetric NO stretching [34]. This is in agreement with the behavior of Amberlyst 
Table 1

Surface area, pore volume, average pore diameter and total ion exchange capacity of the catalysts.

\begin{tabular}{|c|c|c|c|c|c|}
\hline Entry & Catalyst & $\operatorname{AVP}(\mathrm{nm})$ & Pore volume $\left(\mathrm{cm}^{3} \mathrm{~g}^{-1}\right)$ & Surface area $\left(\mathrm{m}^{2} \mathrm{~g}^{-1}\right)$ & TIEC (mequiv. $\mathrm{g}^{-1}$ ) \\
\hline 1 & Amberlyst 15 & 23 & 0.21 & 37 & 4.7 \\
\hline 2 & Amberlyst $15-\mathrm{NO}_{2}{ }^{\mathrm{a}}$ & 27 & 0.22 & 34 & 2.6 \\
\hline 3 & Amberlyst $15-\mathrm{SO}_{3}$ & 25 & 0.26 & 42 & 4.8 \\
\hline 4 & Amberlyst 36 & 22 & 0.05 & 10 & 5.5 \\
\hline 5 & Amberlyst 36- $\mathrm{NO}_{2}$ & 27 & 0.13 & 20 & 5.3 \\
\hline 6 & Amberlyst $36-\mathrm{SO}_{3}$ & 22 & 0.13 & 24 & 5.7 \\
\hline
\end{tabular}

a Elemental analysis of this samples shows a composition of $\mathrm{C}_{26} \mathrm{H}_{34} \mathrm{~N}$.

15 , suggesting that nitration is an effective chemical modification of the cross-linked styrene divinylbenzene resins structure.

\subsection{Reaction profiles}

Figs. 3-5 report typical time-concentrations profiles together with the fitting curves obtained by the kinetic model described in Section 3.2.5. Fig. 3 shows a typical time profile concentration of

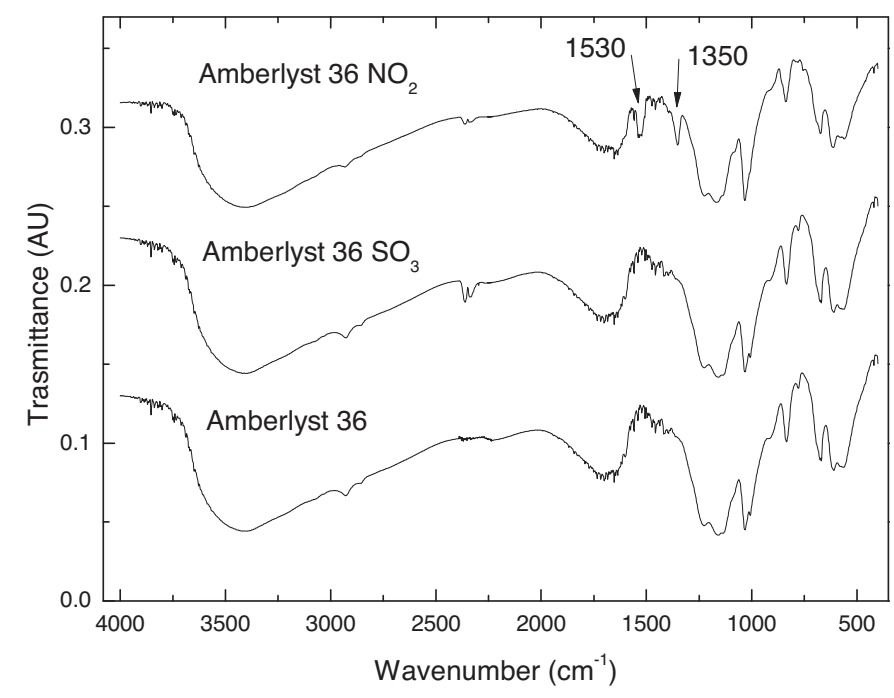

Fig. 2. Comparison of the infrared spectra of neat, sulfonated and nitrated Amberlyst 36 in $\mathrm{KBr}$.

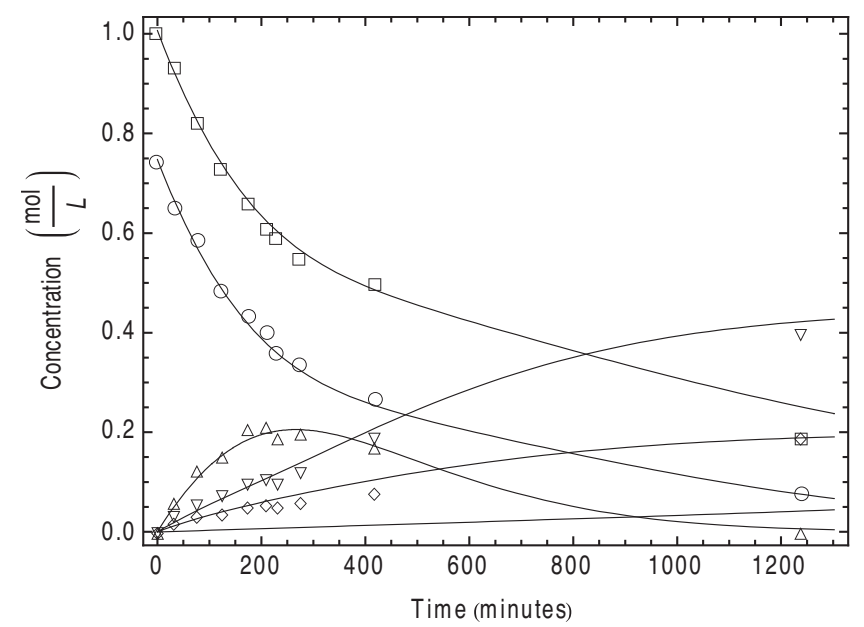

Fig. 3. Time-concentrations and fitting profiles of reagents and products of phenol cyclohexylation catalyzed by Amberlyst 15 . Run conditions: $T, 358 \mathrm{~K}$; phenol, $1.1 \mathrm{~mol} \mathrm{~L}^{-1}$; cyclohexene, $1.2 \mathrm{~mol} \mathrm{~L}^{-1}$; catalyst, $400 \mathrm{mg}$; solvent, 1,2-dichloroethane; solution volume, $10 \mathrm{~mL}$. Cyclohexene $(\square)$, phenol $(\bigcirc)$, cyclohexylphenylether $(\triangle)$, 2-cyclohexylphenol $(\nabla)$, and 4-cyclohexylphenol $(\diamond)$. phenol cyclohexylation, while Fig. 4 shows the trends of formation of the products of di-alkylation and of cyclohexene dimerization. Finally, Fig. 5 shows the trend of phenyl cyclohexyl ether decomposition and the relative fitting which is carried out independently from that of the phenol cyclohexylation.

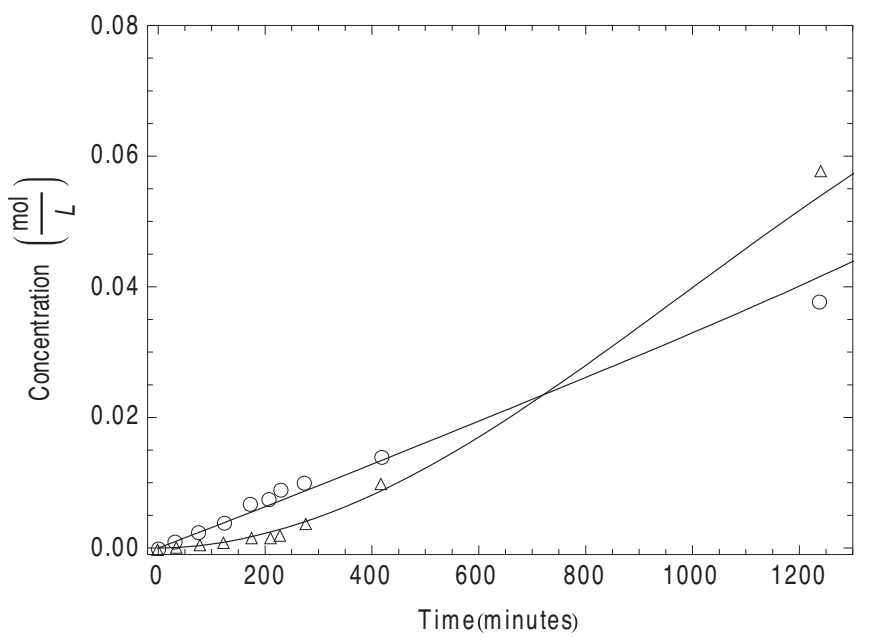

Fig. 4. Time-concentrations and fitting profiles of di-cylohexylphenols and of cyclohexylcyclohexene in phenol cyclohexylation catalyzed by Amberlyst 15. Run conditions: $T, 358 \mathrm{~K}$; phenol, $1.1 \mathrm{~mol} \mathrm{~L}^{-1}$; cyclohexene, $1.2 \mathrm{~mol} \mathrm{~L}^{-1}$; catalyst, $400 \mathrm{mg}$; solvent, 1,2-dichloroethane; solution volume, $10 \mathrm{~mL}$. Cyclohexylcyclohexene $(\bigcirc)$ and di-cyclohexylphenol $(\triangle)$.

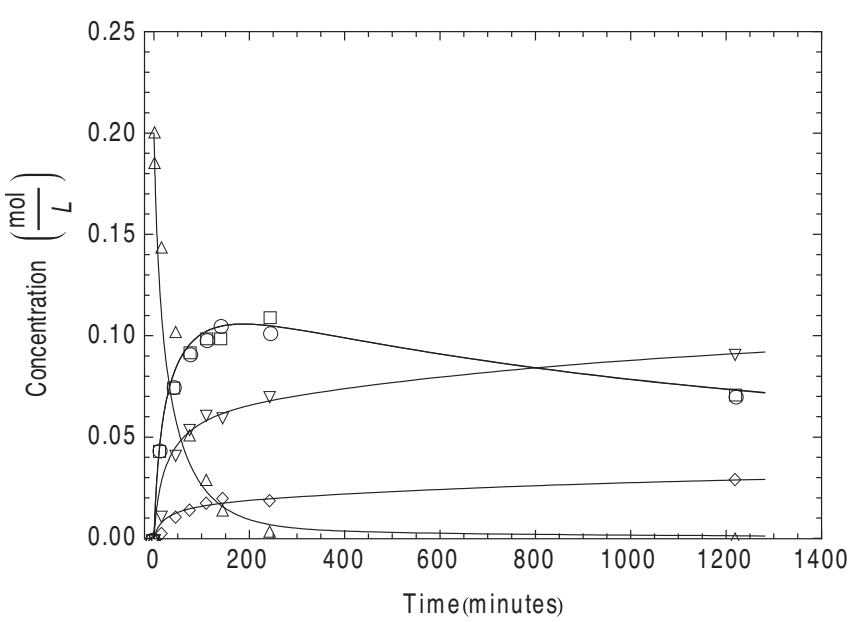

Fig. 5. Time-concentrations and fitting profiles of the reactivity of the cyclohexylphenyl ether in the presence of Amberlyst 15. Run conditions: T, $358 \mathrm{~K}$; cyclohexylphenyl ether, $0.2 \mathrm{~mol} \mathrm{~L}^{-1}$; catalyst, $400 \mathrm{mg}$; solvent, 1,2-dichloroethane; solution volume, $10 \mathrm{~mL}$. Cyclohexene $(\square)$, phenol $(\bigcirc)$, cyclohexylphenylether $(\triangle)$, 2-cyclohexylphenol $(\nabla)$, and 4-cyclohexylphenol $(\diamond)$. 


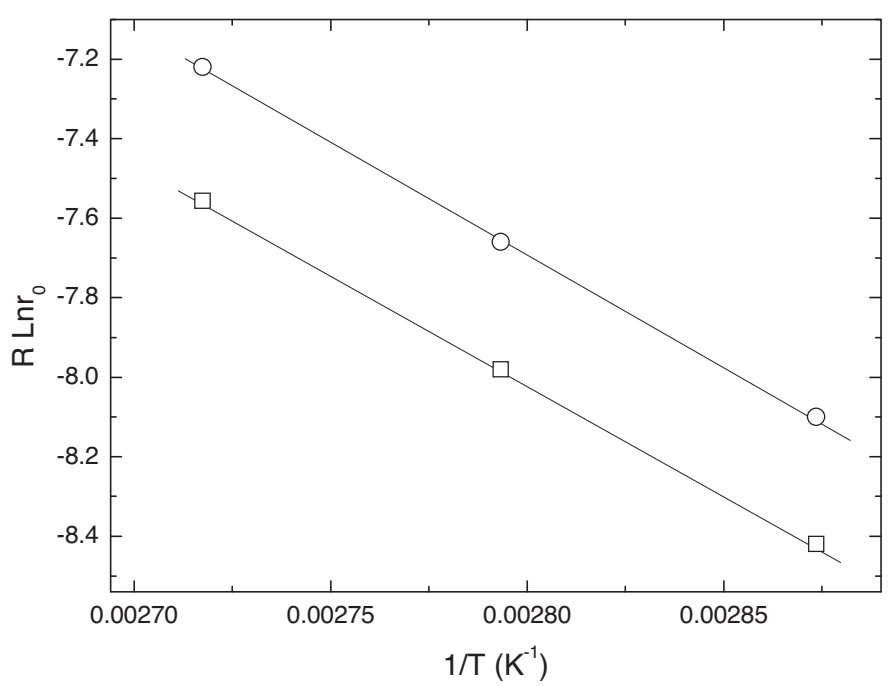

Fig. 6. Arrhenius plot of the initial reaction rate between $348 \mathrm{~K}$ and $368 \mathrm{~K}$ of the reactions catalyzed by Amberlyst $15(\square)$ and Amberlyst $15-\mathrm{NO}_{2}(\bigcirc)$.

\subsubsection{Influence of catalysts, reagents and temperature on the initial reaction rate}

In Table 2 the results obtained in the heterogeneous catalyzed liquid phase cyclohexylation of phenol in the presence of different sulfonic resins as catalyst are reported. We compare the conversion and the selectivity after $4 \mathrm{~h}$ of reaction and the initial reaction rate based on the cyclohexene consumption as a cumulative index of the different kinetics. Selectivity toward O-alkylated and C-alkylated is reported in Table 2. It is evident that products distribution does not change significantly after $4 \mathrm{~h}$ of reaction by varying the catalyst type. It is noteworthy, however, the selectivity in the alkylated products is $95-97 \%$ and it does not change appreciably from $348 \mathrm{~K}$ to $368 \mathrm{~K}$. The main side product is cyclohexyl cyclohexene, which can be decreased to a negligible concentration by using an excess of phenol or by employing nitromethane as a solvent, further discussion well be in Section 3.2.4 [24].

A comparison between commercial and treated resins shows that the latter one is generally more active. Among the treated resins, the most active is Amberlyst 15 nitrated despite of its lower TIEC values. Such evidence suggests a higher activity of the acid sites of the nitrated resin but it is not clear what is the reason of this growth. The apparent activation energy (AAE), calculated by the slope of the Arrhenius plot of the initial reaction rate (e.g. Fig. 6) and reported in Table 2, is practically constant in any case, which suggests that the reaction path is similar for all the catalysts employed.

Experimental data are superimposed in Fig. 7 to the simulation curve of the initial reaction rates obtained by using the model described in Section 3.2.5 (continuous lines). It appears that the initial reaction rate depends on cyclohexene concentration with an almost zero order (c.a. 0.1), while phenol concentration influences the rate with a power law of c.a. 1 (slightly higher). These evidences suggest a complex reaction path where both cyclohexene and phenol are involved in pre-equilibria [36]. This behavior is typical in heterogeneous catalyzed reactions, and can be explained by Langmuir-Hinshelwood type mechanism, but these evidences are not sufficient to asses a unique kinetic model. For this reason, we try to grab some information by studying the equilibrium of etherification in solution (Section 3.2.2) and the heterogeneous equilibrium between reagents and catalyst sites (Section 3.2.3). In addition, by the investigation of the cyclohexene oligomerization we model also the side reaction that affects the overall kinetics (Section 3.2.4). Finally, we develop a kinetic model, which takes into account all the effects of the variation of the operative variables investigated (see Section 3.2.5).

\subsubsection{Equilibrium of etherification of the cyclohexyl phenyl ether from phenol and cyclohexene}

The measurement of the equilibrium of etherification has been carried out by following the trend of decomposition of the cyclohexyl phenyl ether at $358 \mathrm{~K}$ in the presence of methanesulfonic acid (Fig. 8). The use of methanesulfonic acid to promote decomposition of phenyl cyclohexyl ether instead of other acid catalysts is due to its low ring alkylation ability, as already discussed in a previous paper [24]. It appears that the formation of the products of ring alkylation proceeds very slowly compared to the decomposition of the ether. Indeed, the initial reaction rate of decomposition and formation of the cyclohexyl phenyl ether $\left(5.2 \times 10^{-5} \mathrm{~mol} \mathrm{~L}^{-1} \mathrm{~s}^{-1}\right.$ mequiv. $\mathrm{H}^{+}{ }^{-1}$ and $6 \times 10^{-6} \mathrm{~mol} \mathrm{~L}^{-1} \mathrm{~s}^{-1}$ mequiv. $\mathrm{H}^{+}{ }^{-1}$, respectively) are larger than the formation of 2- and 4-cyclohexyl phenol $\left(3.5 \times 10^{-7} \mathrm{~mol} \mathrm{~L}^{-1} \mathrm{~s}^{-1}\right.$ mequiv. $\mathrm{H}^{+}{ }^{-1}$ and $8.9 \times 10^{-8} \mathrm{~mol} \mathrm{~L}^{-1} \mathrm{~s}^{-1}$ mequiv. $\mathrm{H}^{+}{ }^{-1}$, respectively) [23]. These evidences allow to apply the pre-equilibrium approximation to the kinetics of the reaction catalyzed by methanesulfonic acid [29]. In this way, it is possible to calculate, at various temperatures, the experimental equilibrium constants $\left(K_{\text {eq }}\right)$ by substituting the
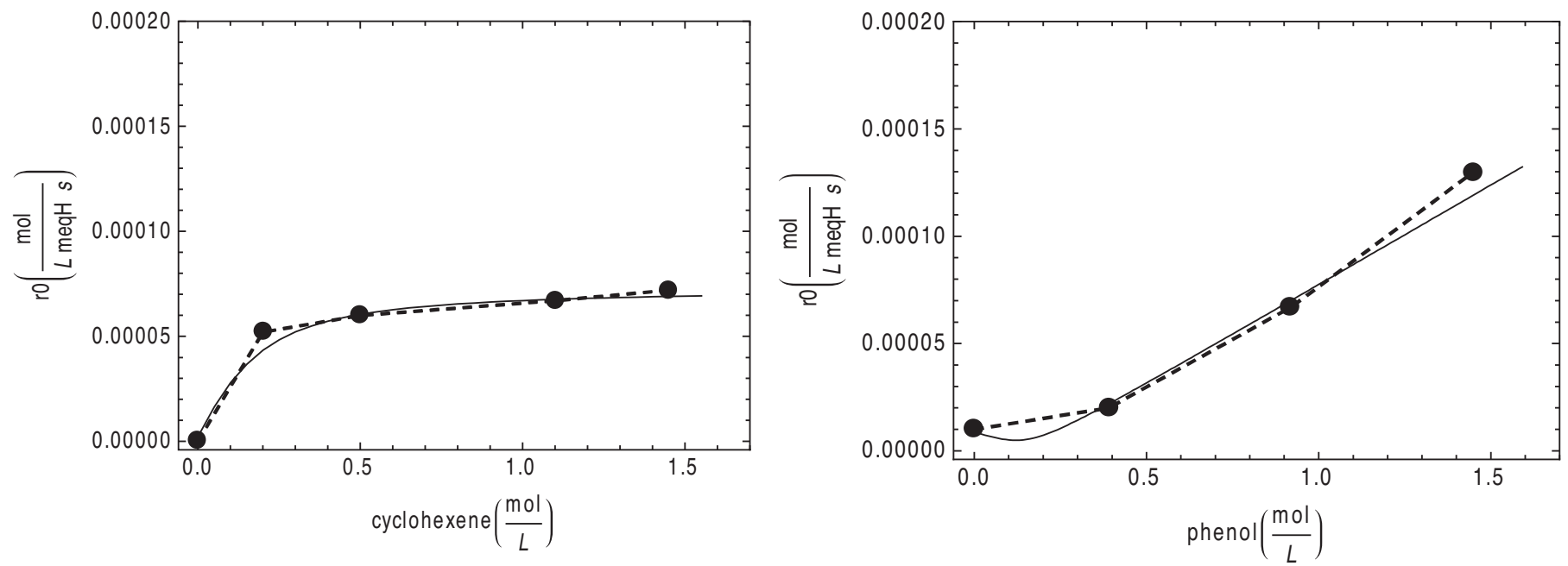

Fig. 7. Influence of reagents concentration on the initial reaction rate at $T 358 \mathrm{~K}$ (dashed line) and simulation by the kinetic model (continuous line). 
Table 2

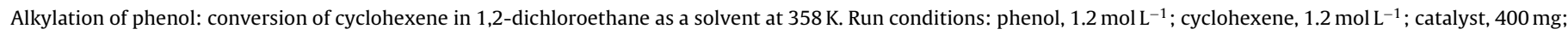
solution volume, $10 \mathrm{~mL}$; stirring speed, $12 \mathrm{~Hz}$.

\begin{tabular}{|c|c|c|c|c|c|c|c|}
\hline \multirow[t]{2}{*}{ Catalyst } & \multirow[t]{2}{*}{ TIEC (mequiv. $\mathrm{g}^{-1}$ ) } & \multirow[t]{2}{*}{ Time (min) } & \multirow[t]{2}{*}{ Conversion (\%) } & \multirow[t]{2}{*}{$r_{0}\left(\times 10^{5} \mathrm{~mol} \mathrm{~L}^{-1} \mathrm{~s}^{-1}\right.$ mequiv. $\left.\mathrm{H}^{+}{ }^{-1}\right)$} & \multicolumn{2}{|c|}{$\begin{array}{l}\text { Selectivity } \\
\text { alkylated (\%) }\end{array}$} & \multirow[t]{2}{*}{$\mathrm{AAE}^{\mathrm{b}}\left(\mathrm{kJ} \mathrm{mol}^{-1}\right)$} \\
\hline & & & & & $\mathrm{O}-\mathrm{Cy}$ & $\mathrm{C}-\mathrm{Cy}$ & \\
\hline \multicolumn{8}{|l|}{ Commercial resins } \\
\hline Amberlyst 15 & 4.7 & 240 & 51 & 6.79 & 52 & 46 & 54 \\
\hline Amberlyst 36 & 5.5 & 240 & 52 & 6.28 & 45 & 53 & 55 \\
\hline \multicolumn{8}{|l|}{ Treated resins } \\
\hline Amberlyst $36-\mathrm{NO}_{2}$ & 5.3 & 240 & 60 & 6.45 & 47 & 50 & 55 \\
\hline Amberlyst $36 \mathrm{SO}_{3}$ & 5.7 & 240 & 57 & 6.33 & 49 & 48 & 55 \\
\hline Amberlyst $15-\mathrm{NO}_{2}$ & 2.6 & 240 & 58 & 10.1 & 44 & 52 & 55 \\
\hline Amberlyst $15-\mathrm{SO}_{3}$ & 4.8 & 240 & 67 & 8.6 & 48 & 49 & 56 \\
\hline
\end{tabular}

a The selectivity does not change significantly from $348 \mathrm{~K}$ to $368 \mathrm{~K}$. O-Cy: cyclohexylphenyl ether and C-Cy: ring alkylated phenols.

b AAE (apparent activation energy) is measured between 348 and $368 \mathrm{~K}$.

values of the concentration of cyclohexyl phenyl ether, phenol, and cyclohexene in Eq. (3), after that the concentrations of phenol and cyclohexene reach a maximum (see, Fig. 8). For instance, at $358 \mathrm{~K}$ after $90 \mathrm{~min}$, the concentrations of cyclohexyl phenyl ether, phenol, and cyclohexene correspond to those of equilibrium while their relatively small and slow variations are due the formation of o- and p-cyclohexyl-phenol. This approximation is not true in the case of heterogeneously catalyzed reaction since adsorption of reagents and products on catalyst sites strongly influence the kinetics of each stage, resulting in a non equilibrium situation; in addition, the rate of ring alkylation is comparable to that of etherification:

$K_{\mathrm{eq}}=\frac{[\mathrm{CPE}]}{[\mathrm{P}][\mathrm{C}]}$

$\Delta G=-R T \operatorname{Ln} K_{\mathrm{eq}}=\Delta H-T \Delta S$

The influence of the temperature on the etherification equilibrium constant has been reported in Table 3 and in Fig. 9. The values of the enthalpy and of the entropy of reaction, calculated by Eq. (4), are $\Delta H=-44,500 \mathrm{~J} \mathrm{~mol}^{-1}, \Delta S=-126 \mathrm{~J} \mathrm{~mol}^{-1} \mathrm{~K}^{-1}$, respectively. These data are in agreement to those to those relative to aliphatic ether such as MTBE and ETBE [37]. The precise thermodynamic value of the equilibrium constant is beyond the scope of this work but its estimated value is functional to the evaluation of the goodness of the kinetic model (see Section 3.2.5).

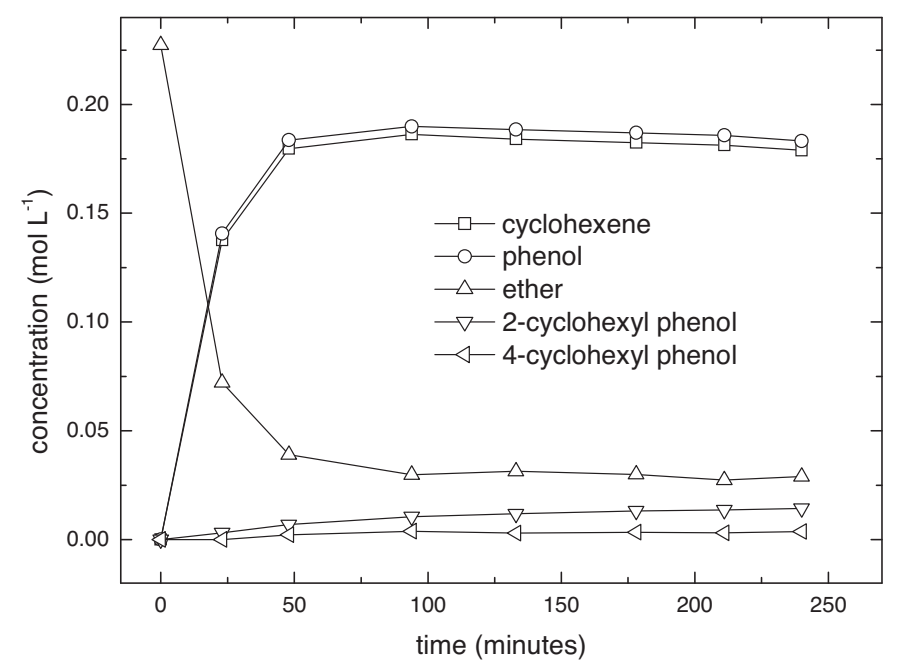

Fig. 8. Time profile concentrations of the cyclohexylphenyl ether decomposition in the presence of $\mathrm{CH}_{3} \mathrm{SO}_{3} \mathrm{H}$, evaluation of the etherification equilibrium. Run conditions: $T$, $358 \mathrm{~K}$; cyclohexylphenyl ether, $0.23 \mathrm{~mol} \mathrm{~L}^{-1} ; \mathrm{CH}_{3} \mathrm{SO}_{3} \mathrm{H}, 180 \mathrm{mg}$; solvent, 1,2-dichloroethane; solution volume, $10 \mathrm{~mL}$.
Table 3

Influence of the temperature on the etherification equilibrium.

\begin{tabular}{lllll}
\hline $\begin{array}{l}\text { Cyclohexene } \\
\left(\mathrm{mol} \mathrm{L}^{-1}\right)\end{array}$ & $\begin{array}{l}\text { Phenol } \\
\left(\mathrm{mol} \mathrm{L}^{-1}\right)\end{array}$ & $\begin{array}{l}\mathrm{CPE} \\
\left(\mathrm{mol} \mathrm{L}^{-1}\right)\end{array}$ & $K_{\mathrm{eq}}\left(\mathrm{L} \mathrm{mol}^{-1}\right)$ & $T(\mathrm{~K})$ \\
\hline 0.164 & 0.171 & 0.033 & 1.18 & 348 \\
0.186 & 0.19 & 0.03 & 0.85 & 358 \\
0.202 & 0.201 & 0.0209 & 0.51 & 368 \\
\hline
\end{tabular}

The associated error is $6-8 \%$ calculated from the standard deviation of the constants.

\subsubsection{Adsorption equilibria}

In Fig. 10 the adsorption isotherms at $298 \mathrm{~K}$ of cyclohexene, phenol, cyclohexyl phenyl ether and the combined adsorption of cyclohexene on pre-adsorbed phenol are reported. It appears that neat cyclohexene and cyclohexyl phenyl ether are adsorbed in a negligible extent. On the contrary, phenol reaches a saturation value of 1.7 mequiv.gcat at $1 \mathrm{~mol} \mathrm{~L}^{-1}$ of concentration and a Langmuir adsorption model is used to fit experimental data and the equilibrium constant were measured at low coverage [31].

The influence of the temperature on the adsorption equilibrium constant is reported in Fig. 11 and in Table $4 . \Delta H$ of adsorption $\left(\Delta H=-38,000 \mathrm{~J} \mathrm{~mol}^{-1}\right)$ is quite low to account for a chemical bond between phenol and sulfonic group, but it is compatible to the formation of hydrogen bonds. The same adsorption model employed for phenol is used for cyclohexene on pre-adsorbed phenol, and their saturation value reaches a value of 1.9 mequiv. $\mathrm{g}^{-1}$ at cyclohexene concentration of $1 \mathrm{~mol} \mathrm{~L}^{-1}$. The measured $\Delta H$ of adsorption $\left(\Delta H=-22,000 \mathrm{~J} \mathrm{~mol}^{-1}\right)$ is lower than that found for

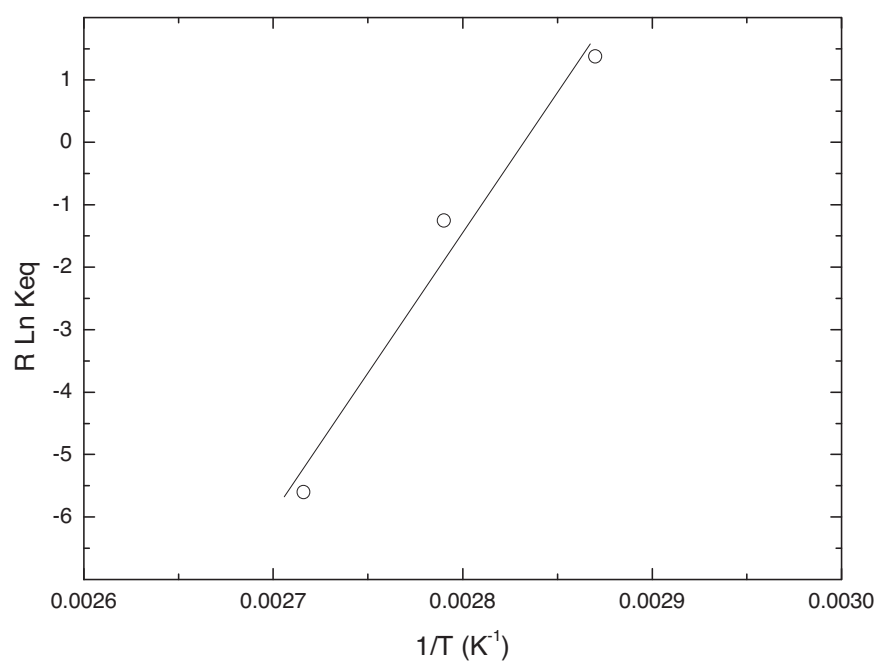

Fig. 9. Influence of the temperature between $348 \mathrm{~K}$ and $368 \mathrm{~K}$ on the etherification equilibrium: $\Delta H=-44,500 \mathrm{~J} \mathrm{~mol}^{-1}$ and $\Delta S=-126 \mathrm{~J} \mathrm{~mol}^{-1} \mathrm{~K}^{-1}$. 


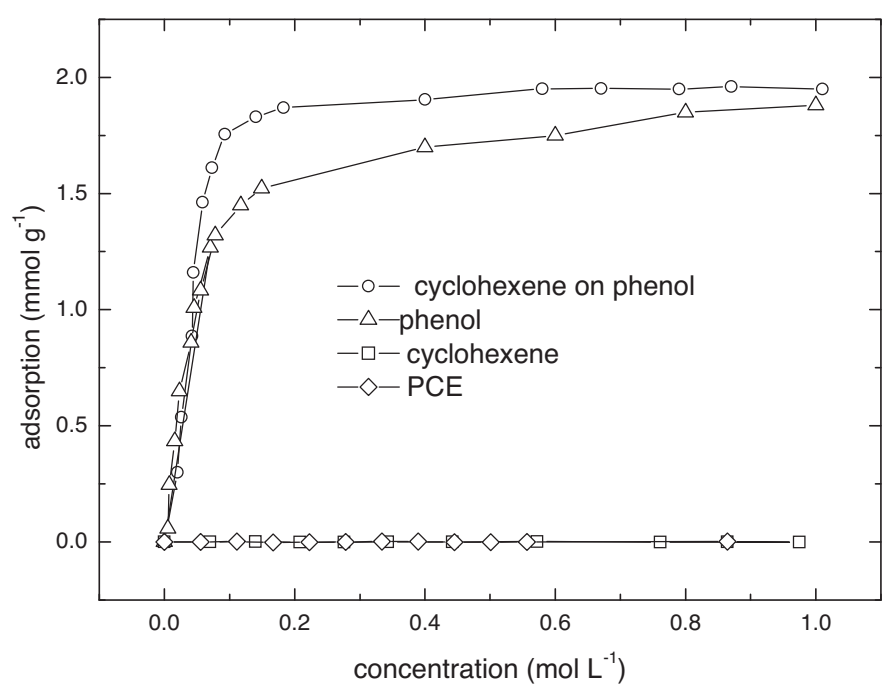

Fig. 10. Adsorption isotherm at $298 \mathrm{~K}$ of phenol, cyclohexene, cyclohexene on phenol and of cyclohexylphenyl ether on Amberlyst 15. Run conditions: catalyst, $800 \mathrm{mg}$; solution volume, $10 \mathrm{~mL}$; solvent, 1,2-dichoroethane.

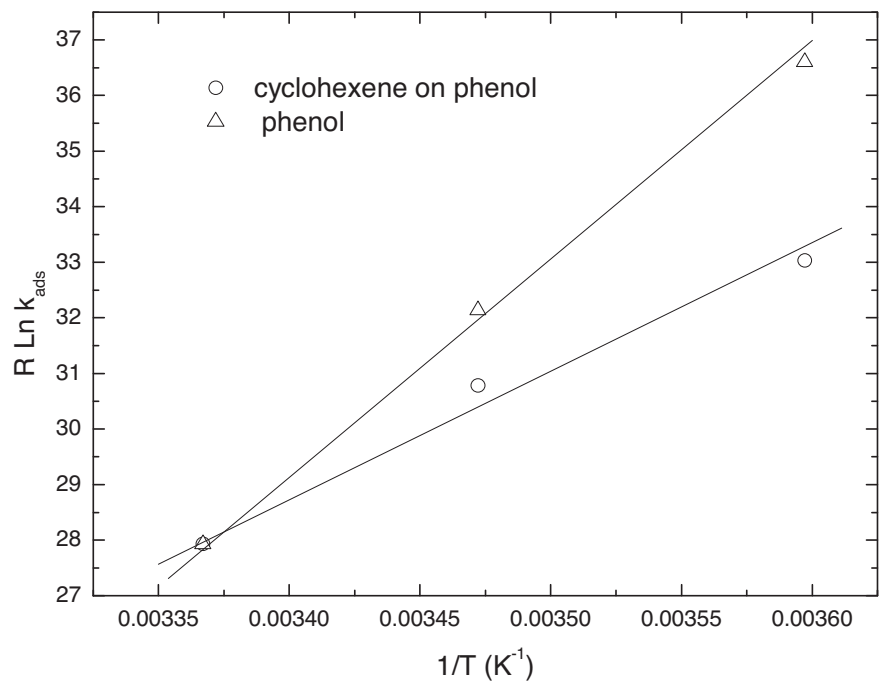

Fig. 11. Adsorption equilibrium on Amberlyst 15 between $278 \mathrm{~K}$ and $298 \mathrm{~K}$. Run conditions: catalyst, $800 \mathrm{mg}$; solution volume, $10 \mathrm{~mL}$; solvent, $1,2-$ dichoroethane. $\Delta H=-37,613 \mathrm{~J} \mathrm{~mol}^{-1}, \Delta S=-99 \mathrm{~J} \mathrm{~mol}^{-1} \mathrm{~K}^{-1}, \quad$ cyclohexene on phenol $\Delta H=-22,015 \mathrm{~J} \mathrm{~mol}^{-1}, \Delta S=-46 \mathrm{~J} \mathrm{~mol}^{-1} \mathrm{~K}^{-1}$.

\section{Table 4}

Influence of temperature on Adsorption equilibrium constant, and extrapolation at the temperatures of reaction.

\begin{tabular}{lll}
\hline$T$ adsorption $(\mathrm{K})$ & Phenol $K_{\mathrm{HP}}$ & Cyclohexene on phenol $K_{\mathrm{HPC}}$ \\
\hline $\begin{array}{l}\text { Measured } \\
297\end{array}$ & 31 & 32 \\
288 & 52 & 44 \\
278 & 90 & 58 \\
& $\Delta H=-38,000 \mathrm{~J} \mathrm{~mol}^{-1}$ & $\Delta H=-21,000 \mathrm{~J} \mathrm{~mol}^{-1}$ \\
& $\Delta S=-100 \mathrm{~J} \mathrm{~mol}^{-1} \mathrm{~K}^{-1}$ & $\Delta S=-44 \mathrm{~J} \mathrm{~mol}^{-1} \mathrm{~K}^{-1}$ \\
Extrapolated using Eq. (4) & \\
348 & 2.3 & 8.7 \\
358 & 1.6 & 6.8 \\
368 & 1.2 & 5.5
\end{tabular}

The associated error is 5-6\% calculated from the linear fitting at low coverage.

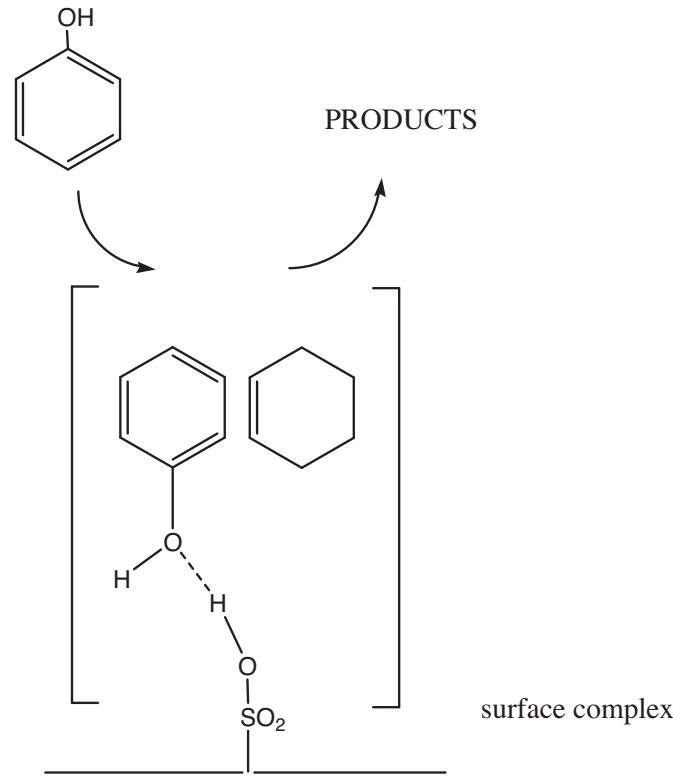

Fig. 12. Proposed surface reaction mechanism.

phenol, suggesting a weaker interaction between olefin and the system sulfonic resin + phenol (Fig. 10). No ether formation is observed at $298 \mathrm{~K}$. The negligible adsorption of both neat cyclohexene and cyclohexylphenyl ether can be ascribed to the absence of strong hydrogen bonds, which are responsible for phenol adsorption (see later).

In Table 4 the measured adsorption equilibrium constants (obtained at 278-298 K) are reported together with those extrapolated by Eq. (4) from $348 \mathrm{~K}$ to $368 \mathrm{~K}$, which will be employed in the evaluation of the kinetic model in Section 3.2.5. Such a procedure does not allow to know the real values of the adsorption constant at the temperatures of reaction, in fact, at those temperatures many reactions occur, with a different surface population and consequently with a different free energy. However, this is useful to fix the value of the adsorption constants in the kinetic model with measured parameters whose values should be straightforward related to the real ones. In this way, it is possible to implement a kinetic model, whose fitting variables are only kinetic constants.

In order to explain the trend of the initial rate of reaction vs. both cyclohexene and phenol concentrations (Fig. 7), together with the adsorption behavior of reagents and products, it is necessary to suppose a reaction mechanism, where both a quite strong phenol-cyclohexene adsorption and a strictly dependence of the rate of reaction from the phenol concentration occur simultaneously. This can be modeled by supposing a surface complex formed by phenol and cyclohexene adsorbed on a sulfonic group of the resin reacting with a molecule of phenol in solution (see Fig. 12). In this way, it is possible to explain the strong adsorption behavior of phenol, the adsorption of cyclohexene on pre-adsorbed phenol and their reaction orders (3/2 and zero for phenol and cyclohexene, respectively). Except kinetic and adsorption data, there are no direct experimental evidences of the formation of such a surface complex. For this reason, we try to grab some information from experiments in homogeneous non aqueous solution of $\mathrm{CH}_{3} \mathrm{SO}_{3} \mathrm{H}$.

The interactions between $\mathrm{CH}_{3} \mathrm{SO}_{3} \mathrm{H}$ and cyclohexene in the presence and absence of phenol are investigated. Then, ${ }^{13} \mathrm{C}\left\{{ }^{1} \mathrm{H}\right\}$ are studied by NMR at $243 \mathrm{~K}$ and the chemical shifts are reported in Table 5. In the experimental conditions described, no signals attributable to carbocation or ester formation were detected and no reaction product was observed $[38,39]$. Addition of incremental 
Table 5

${ }^{13} \mathrm{C}\left\{{ }^{1} \mathrm{H}\right\}$ NMR data for $\mathrm{CDCl}_{3}$ solutions of cyclohexene, phenol, cyclohexyl phenyl ether and methanesulfonic acid at $243 \mathrm{~K}$. Chemical shifts are reported in ppm.

\begin{tabular}{|c|c|c|c|c|c|c|c|c|c|}
\hline Acid/cyclohexene (molar ratio) & \multicolumn{4}{|c|}{ Cyclohexene (chemical shifts) } & \multicolumn{5}{|c|}{$\mathrm{CH}_{3} \mathrm{SO}_{3} \mathrm{H}$ (chemical shifts) } \\
\hline \multicolumn{10}{|l|}{ Acid + cyclohexene } \\
\hline $0 / 1$ & 127.2 & & 24.9 & & 22.3 & & & & \\
\hline $0.25 / 1$ & 127.2 & & 24.9 & & 22.3 & 39 & & $39.0 \mathrm{br}^{\mathrm{a}}$ & \\
\hline $0.5 / 1$ & 127.1 & & 24.9 & & 22.3 & 39 & & $39.0 \mathrm{br}$ & \\
\hline $0.75 / 1$ & 127.1 & & 24.9 & & 22.3 & 39 & & $38.8 \mathrm{br}$ & 38.5 \\
\hline $1 / 1$ & 127.1 & & 24.9 & & 22.3 & 39 & & $38.9 \mathrm{br}$ & 38.5 \\
\hline $1.5 / 1$ & 127.1 & & 24.9 & & 22.3 & 39 & & $38.9 \mathrm{br}$ & 38.5 \\
\hline $2 / 1$ & 127.1 & & 24.9 & & 22.3 & 39 & & $38.8 \mathrm{br}$ & 38.4 \\
\hline Acid/cyclohexene (molar ratio) & \multicolumn{4}{|c|}{ Phenol (chemical shifts) } & & & & \multicolumn{2}{|c|}{$\mathrm{CH}_{3} \mathrm{SO}_{3} \mathrm{H}$ (chemical shifts) } \\
\hline \multicolumn{10}{|l|}{ Acid + phenol } \\
\hline $0 / 1$ & 154.3 & & 129.7 & & 121.0 & & & & \\
\hline $0.25 / 1$ & 153.8 & & 129.7 & & 121.3 & & & 39.1 & \\
\hline $0.5 / 1$ & 153.3 & & 129.7 & & 121.6 & & & 39.1 & \\
\hline $0.75 / 1$ & 152.9 & & 129.7 & & 121.8 & & & 39.0 & \\
\hline $1 / 1$ & 152.8 & & 129.7 & & 121.8 & & & 39.0 & \\
\hline $1.5 / 1$ & 153.0 & & 129.7 & & 121.7 & & & 39.0 & \\
\hline $2 / 1$ & 152.9 & & 129.7 & & 121.7 & & & 39.0 & \\
\hline Acid/cyclohexyl phenyl (molar ratio) & \multicolumn{4}{|c|}{ Cyclohexyl phenyl ether (chemical shifts) } & & & & \multicolumn{2}{|c|}{$\mathrm{CH}_{3} \mathrm{SO}_{3} \mathrm{H}$ (chemical shifts) } \\
\hline \multicolumn{10}{|l|}{ Acid + cyclohexyl phenyl ether } \\
\hline $0 / 1$ & 157.1 & 129.3 & 120.1 & 115.3 & $31.5 \mathrm{br}$ & 25.3 & $23.9 \mathrm{br}$ & & \\
\hline $0.25 / 1$ & 156.5 & 129.4 & 120.8 & 115.9 & $31.5 \mathrm{br}$ & 25.2 & $23.9 \mathrm{br}$ & 39.1 & \\
\hline $0.5 / 1$ & 156.7 & 129.4 & 120.5 & 115.7 & $31.5 \mathrm{br}$ & 25.3 & $23.8 \mathrm{br}$ & 39.1 & \\
\hline $0.75 / 1$ & 156.7 & 129.4 & 120.7 & 115.7 & $31.5 \mathrm{br}$ & 25.2 & $23.8 \mathrm{br}$ & 39.1 & $38.8 \mathrm{br}$ \\
\hline $1 / 1$ & 156.7 & 129.4 & 120.6 & 115.7 & $31.5 \mathrm{br}$ & 25.2 & $23.8 \mathrm{br}$ & 39.1 & $38.8 \mathrm{br}$ \\
\hline $1.5 / 1$ & 156.7 & 129.4 & 120.6 & 115.7 & $31.5 \mathrm{br}$ & 25.2 & $23.8 \mathrm{br}$ & 39.1 & $38.8 \mathrm{br}$ \\
\hline $2 / 1$ & 156.7 & 129.4 & 120.6 & 115.7 & $31.5 \mathrm{br}$ & 25.2 & $238 \mathrm{br}$ & 39.1 & $38.8 \mathrm{br}$ \\
\hline Acid/cyclohexene (molar ratio) & \multicolumn{3}{|c|}{ Cyclohexene (chemical shifts) } & \multicolumn{2}{|c|}{ Phenol (chemical shifts) } & & & \multicolumn{2}{|c|}{$\mathrm{CH}_{3} \mathrm{SO}_{3} \mathrm{H}$ (chemical shifts) } \\
\hline \multicolumn{10}{|l|}{ Acid + cyclohexene + phenol } \\
\hline $0 / 1 / 1$ & 127.2 & 24.9 & 22.3 & 154.4 & 129.7 & 120.9 & 115.1 & & \\
\hline $0.25 / 1 / 1$ & 127.2 & 24.9 & 22.3 & 153.6 & 129.7 & 121.3 & 115.1 & 39.0 & \\
\hline $0.5 / 1 / 1$ & 127.1 & 24.8 & 22.3 & 153.4 & 129.7 & 121.4 & 115.1 & 39.0 & \\
\hline $0.75 / 1 / 1$ & 127.1 & 24.8 & 22.2 & 153.2 & 129.7 & 121.5 & 115.1 & 38.9 & \\
\hline $1 / 1 / 1$ & 127.1 & 24.8 & 22.2 & 153.1 & 129.7 & 121.6 & 115.0 & 38.9 & \\
\hline $1.5 / 1 / 1$ & 127.1 & 24.8 & 22.2 & 153.0 & 129.7 & 121.6 & 115.0 & 39.0 & \\
\hline $2 / 1: 1$ & 127.1 & 24.8 & 22.2 & 153.0 & 129.6 & 121.7 & 115.0 & 38.9 & \\
\hline
\end{tabular}

br: broad.

amounts of $\mathrm{CH}_{3} \mathrm{SO}_{3} \mathrm{H}$ to a $1 \mathrm{~mol} \mathrm{~L}^{-1} \mathrm{CDCl}_{3}$ solution of cyclohexene did not cause any meaningful variation of the olefin chemical shifts. Cyclohexene appeared to be insensitive to the acid addition also in the presence of phenol, while the variations of chemical shifts on increasing the acid concentration for phenol O-bonded carbon atom and, to a lesser extent, for the para-carbon atom agree with the formation of an adduct between $\mathrm{CH}_{3} \mathrm{SO}_{3} \mathrm{H}$ and phenol. Measurements on phenol/acid mixtures showed that the interaction between these two species is not sensitive to the presence of cyclohexene. It is noteworthy that in the absence of phenol the ${ }^{13} \mathrm{C}$ $\left\{{ }^{1} \mathrm{H}\right\}$ NMR spectra of $\mathrm{CH}_{3} \mathrm{SO}_{3} \mathrm{H}$ show a variable number of signals in the range 38-39 ppm depending upon acid concentration. When a low quantity of acid is present in the NMR tube a sharp singlet at $39.3 \mathrm{ppm}$ and a broad signal around $39.0 \mathrm{ppm}$ are detectable. On increasing $\mathrm{CH}_{3} \mathrm{SO}_{3} \mathrm{H}$ the relative intensity of the broad signal increases and a new sharp singlet around $38.5 \mathrm{ppm}$ appears, whose relative intensity grows on acid addition. These observations are indicative of the formation of quite complex mixtures of methanesulfonic acid adducts in the absence of phenol. When also phenol is present in solution, instead, only a sharp singlet around $39.0 \mathrm{ppm}$ is detectable in the acid range considered, this confirming the existence of relatively strong interactions between $\mathrm{CH}_{3} \mathrm{SO}_{3} \mathrm{H}$ and phenol. Finally, cyclohexyl phenyl ether chemical shifts are not significantly affected by the presence of methanesulfonic acid in the described experimental conditions, as deducible from Table 5. The data reported suggest only a very weak interaction between ether and $\mathrm{CH}_{3} \mathrm{SO}_{3} \mathrm{H}$.
These results obtained in $\mathrm{CDCl}_{3}$ in the presence of methanesulfonic acid are in agreement to the formation of hydrogen bonded phenol to the sulfonic group of the resin thus allowing its adsorption on the catalyst. Additionally, the negligible interaction of both the olefin and the ether with the methane sulfonic acid is in agreement to their poor tendency to adsorb on the sulfonic resin. On the contrary, the results of the NMR measurements in solutions do not allow any explanation relative to the large values of cyclohexene adsorption on pre-adsorbed phenol. However, the quite low values of the $\Delta H$ of adsorption of cyclohexene measured on the resin-phenol system suggest a specific physical interaction of the cyclohexene with the sulfonic resin. As a matter of fact, the only measurable interaction of methanesulfonic acid with phenol and cyclohexene is physical in nature, probably for this reason, equilibria in solution are not easily measurable by NMR.

\subsubsection{Oligomerization of cyclohexene}

Regarding side reactions, cyclohexene oligomerization (practically only dimerization) is the one which may significantly affect the kinetics and for this reason it must be accounted for in the overall kinetic model. In Fig. 13 the comparison of the trends of cyclohexene dimerization in the absence and in the presence of phenol is reported. The reaction has been carried out in the absence of phenol with Amberlyst 15 as a catalyst at $358 \mathrm{~K}$ and in 1,2dichloroethane as a solvent. Cyclohexene disappears with an initial reaction rate of about $3 \times 10^{-5} \mathrm{~s}^{-1}$ mequiv. H+ $^{-1}$, which is 25 times higher than that measured in the presence of phenol. In addition, 


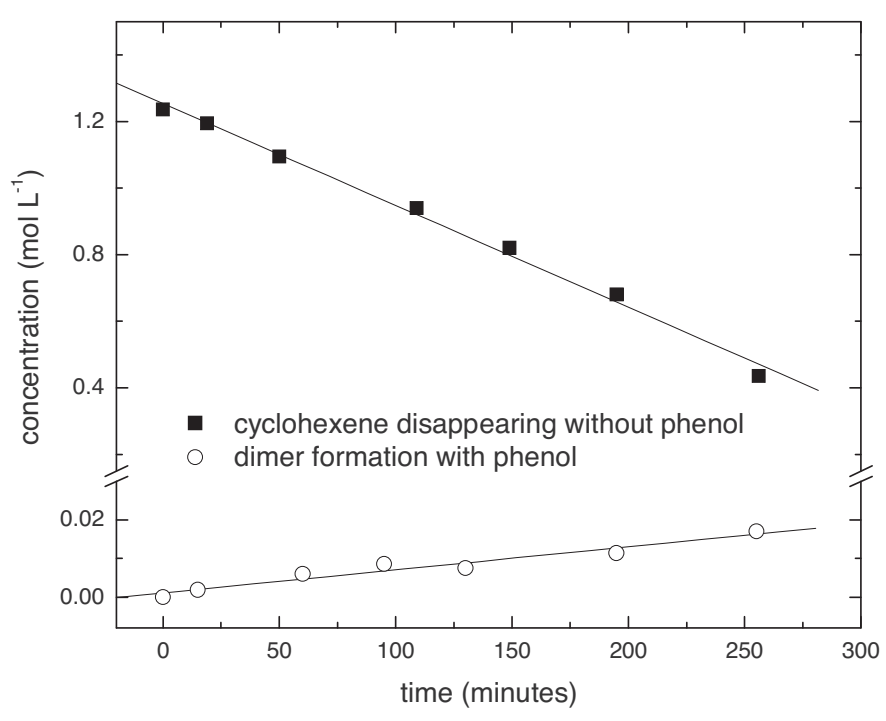

Fig. 13. Cyclohexene dimerization/oligomerization in the absence and in the presence of phenol. Run conditions: cyclohexene, $1.2 \mathrm{~mol} \mathrm{~L}^{-1}$; catalyst, $400 \mathrm{mg}$; solution volume, $10 \mathrm{~mL}$. Phenol $1 \mathrm{~mol} \mathrm{~L}^{-1}$ when phenol is present.

we found a complex mixture of isomers and oligomers, very different to the composition of products formed in the presence of phenol. It is noteworthy that in both cases an almost linear profile is observed, thus suggesting the constancy of the active specie as the concentration of cyclohexene decrease.

The lower reaction rate, observed in the reaction carried out with phenol and its different product distribution, is likely due to the inhibiting effect of the phenol on the cyclohexene oligomerization, for the steric hindrance of the species adsorbed on the surface of the catalyst. A detailed study of this reaction is beyond the scope of this work, but now it is clear that the dimerization of cyclohexene affects the overall kinetic and an equation for explaining this reaction must be included in the kinetic model.

\subsubsection{Kinetic model and evaluation of the kinetic parameters}

In this section we try to develop a kinetic model starting from the experimental evidences described in previous sections. As a matter of fact, an Eley-Rideal type mechanism, where phenol in solution reacts with a surface electrophilic complex, is proposed also by Yadav and Kumar [18]. They studied the kinetics of reaction in solvent-less conditions, but in that paper some aspects relative to adsorption and etherification equilibria are not considered [18]. Starting from those studies, we implement both the etherification and the adsorption equilibria in the kinetic model, thus allowing a comprehensive explanation of the phenomena (see Fig. 5).

In Scheme 1 the proposed reaction stages are reported: reactions ( 1 ) and (2) are the surface equilibrium, between reagent and the surface acid site $(\mathrm{H})$; (3) and (4) are the equations of the etherification equilibrium, in which direct and reverse have different interactions with catalyst surface; reactions (5)-(7) are the alkylation of phenol; (8) and (9) are the rearrangement of the cyclohexyl phenyl ether; finally steps (10) and (11) are the dicyclohexylation of phenol and the dimerization of cyclohexene, respectively. Eqs. (6)-(15) derive from the previous stages and by taking into consideration the following assumptions:

(i) all the reactions are acid catalyzed, and the sites of the catalyst are energetically equivalent at any grade of coverage;

(ii) phenol is adsorbed, pure cyclohexene is negligibly adsorbed but is adsorbed in the presence of phenol;

(iii) phenol attacks the cyclohexene-phenol complex on the catalyst surface by an Eley-Rideal mechanism;
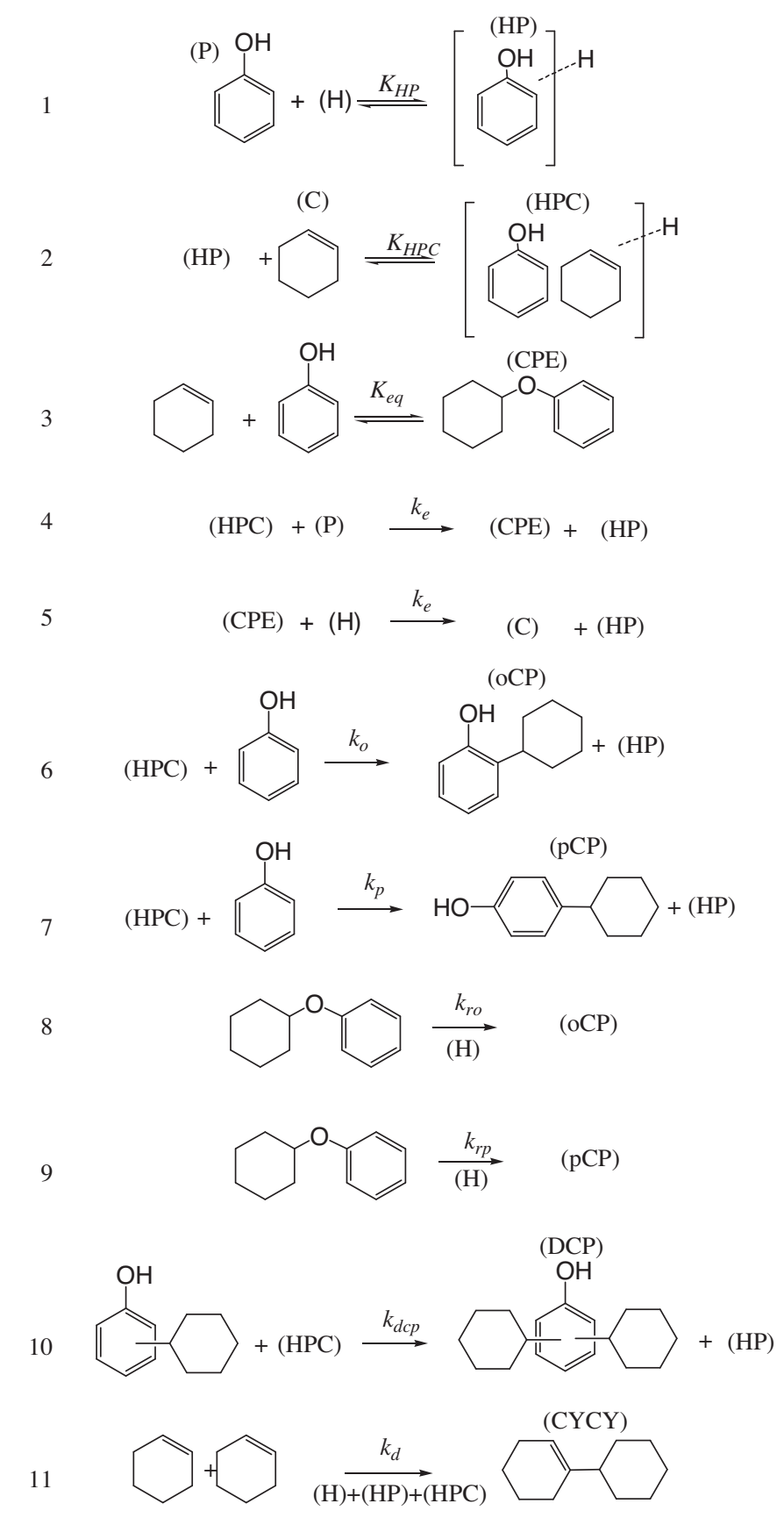

Scheme 1. Reactions stages of phenol cyclohexylation on sulfonic resins. $(H)$ is the proton of the sulfonic resin.

(iv) cyclohexyl phenyl ether is negligibly adsorbed on catalyst surface;

(v) cyclohexyl phenyl ether decomposition and rearrangement are catalyzed by acid sites $(\mathrm{H})$ and both reactions are of first order on ether concentration in agreement to the negligible adsorption behavior;

(vi) di-cyclohexylation occurs by a consecutive alkylation by Eley-Rideal mechanism between the surface complex and the alkylphenol in solution;

(vii) cyclohexene dimerization is catalyzed by all kinds of acid sites and shows a zero apparent order of reaction in the cyclohexene concentration;

(viii) a cumulative mass balance for reagents and acid sites (Eq. (14)) needs in order to reach numerical convergence of the system of algebraic and differential equations [40]. 
$K_{\mathrm{HP}}=\frac{[\mathrm{HP}]}{[\mathrm{H}][\mathrm{P}]}$

$K_{\mathrm{HPC}}=\frac{[\mathrm{HPC}]}{[\mathrm{HP}][\mathrm{C}]}$

$$
\begin{aligned}
- & \frac{d[\mathrm{P}]}{d t}=k_{\mathrm{e}}[\mathrm{HPC}][\mathrm{P}]-k_{\mathrm{er}}[\mathrm{CPE}][\mathrm{H}]+k_{0}[\mathrm{HPC}][\mathrm{P}]+k_{\mathrm{p}}[\mathrm{HPC}][\mathrm{P}] \\
& +k_{\mathrm{dcp}}[\mathrm{HPC}]([\mathrm{oCP}]+[\mathrm{pCP}])
\end{aligned}
$$

$\frac{d[\mathrm{CPE}]}{d t}=k_{\mathrm{e}}[\mathrm{HPC}][\mathrm{P}]-k_{\mathrm{er}}[\mathrm{CPE}][\mathrm{H}]-k_{\mathrm{ro}}[\mathrm{CPE}][\mathrm{H}]-k_{\mathrm{rp}}[\mathrm{CPE}][\mathrm{H}]$

$\frac{d[\mathrm{oCP}]}{d t}=k_{\mathrm{ro}}[\mathrm{CPE}][\mathrm{H}]+k_{\mathrm{o}}[\mathrm{HPC}][\mathrm{P}]$

$\frac{d[\mathrm{pCP}]}{d t}=k_{\mathrm{rp}}[\mathrm{CPE}][\mathrm{H}]+k_{\mathrm{p}}[\mathrm{HPC}][\mathrm{P}]$

$$
-\frac{d[\mathrm{C}]}{d t}=k_{\mathrm{e}}[\mathrm{HPC}][\mathrm{P}]-k_{\mathrm{er}}[\mathrm{CPE}] \mathrm{H}+k_{\mathrm{o}}[\mathrm{HPC}][\mathrm{P}]+k_{\mathrm{p}}[\mathrm{HPC}][\mathrm{P}]
$$$$
+k_{\mathrm{dcp}}[\mathrm{HPC}]([\mathrm{oCP}]+[\mathrm{pCP}])+k_{\mathrm{d}}([\mathrm{HPC}]+[\mathrm{HP}]+[\mathrm{H}])
$$

$$
\frac{d([\mathrm{CYCY}])}{d t}=k_{\mathrm{d}}([\mathrm{HPC}]+[\mathrm{HP}]+\mathrm{H})
$$$$
\left[\mathrm{P}_{0}\right]+\left[\mathrm{C}_{0}\right]+\left[\mathrm{H}_{\mathrm{t}}\right]=[\mathrm{P}]+[\mathrm{C}]+[\mathrm{H}]+3[\mathrm{HPC}]+2[\mathrm{HP}]+2[\mathrm{CPE}]
$$$$
+2[\mathrm{oCP}]+2[\mathrm{pCP}]+3[\mathrm{DCP}]+2[\mathrm{CICI}]
$$

Eq. (15) represents the rate of formation of cyclohexylphenyl ether and it is zero at the maximum of the concentration profile of the cyclohexylphenyl ether (see Fig. 4 ). In this way, $k_{\mathrm{er}}$ can be calculated directly, from Eq. (16). This is obtained from Eq. (15) by neglecting the terms $k_{\mathrm{ro}}[\mathrm{CPE}][\mathrm{H}]-k_{\mathrm{rp}}[\mathrm{CPE}][\mathrm{H}]$, which are relative to the ether rearrangement and being much smaller compared to those of the etherification. For this reason $k_{\mathrm{er}}$ is not considered a fitting variable but an implicit function of $k_{\mathrm{e}}, K_{\mathrm{HP}}, K_{\mathrm{HPC}}$ and $K_{\mathrm{eq}}$ (adsorption and etherification equilibrium constant). In this way, $k_{\mathrm{er}}$ is calculated from Eqs. (3), (5), (6) and (16) from available equilibrium and kinetic constant, thus reducing the number of the fitting variables by one:

$$
\begin{aligned}
0 & =\frac{d[\mathrm{CPE}]}{d t}=k_{\mathrm{e}}[\mathrm{HPC}][\mathrm{P}]-k_{\mathrm{er}}[\mathrm{CPE}][\mathrm{H}]-k_{\mathrm{ro}}[\mathrm{CPE}][\mathrm{H}] \\
& -k_{\mathrm{rp}}[\mathrm{CPE}][\mathrm{H}]
\end{aligned}
$$

$$
0=\frac{d[\mathrm{CPE}]}{d t}=k_{\mathrm{e}}[\mathrm{HPC}][\mathrm{P}]-k_{\mathrm{er}}[\mathrm{CPE}][\mathrm{H}]
$$

The numerical solution of the complete set of equations ((3) and (8)-(16)) allows the fitting of the experimental data $[32,33,40]$. Typical results have been reported in Figs. 3-5. It is noteworthy, the good agreement between the effect of phenol and cyclohexene concentration on the initial reaction rate and its simulation obtained by using the fitted kinetic constants. A further proof of the goodness of the model is the detailed description of the differences in the ortho/para selectivity observed between the reactions of phenol cyclohexylation and cyclohexylphenyl ether rearrangement [24]. This behavior is related to the amount of products of ring alkylation formed by the two routes. Indeed, it is well known that ortho isomer is favored via rearrangement and this is evident by

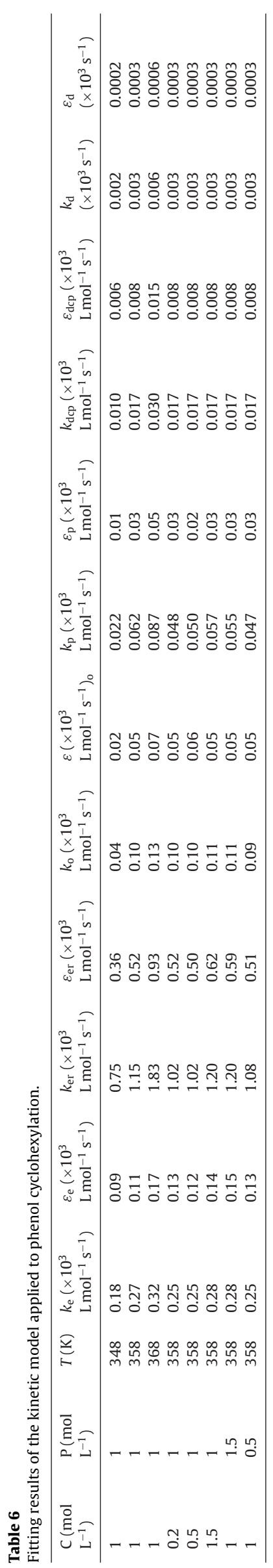


Table 7

Fitting results of the kinetic model applied to cyclohexyl phenyl ether decomposition at substrate concentration of 0.2 mol $\mathrm{L}^{-1}$

\begin{tabular}{|c|c|c|c|c|}
\hline$T(\mathrm{~K})$ & $k_{\mathrm{ro}}\left(\times 10^{3} \mathrm{Lmol}^{-1} \mathrm{~s}^{-1}\right)$ & $\varepsilon_{\mathrm{ro}}\left(\times 10^{3} \mathrm{~L} \mathrm{~mol}^{-1} \mathrm{~s}^{-1}\right)$ & $k_{\mathrm{rp}}\left(\times 10^{3} \mathrm{Lmol}^{-1} \mathrm{~s}^{-1}\right)$ & $\varepsilon_{\mathrm{rp}}\left(\times 10^{3} \mathrm{~L} \mathrm{~mol}^{-1} \mathrm{~s}^{-1}\right)$ \\
\hline 348 & 1.25 & 0.11 & 0.28 & 0.025 \\
\hline 358 & 1.57 & 0.13 & 0.37 & 0.036 \\
\hline 368 & 1.83 & 0.15 & 0.47 & 0.044 \\
\hline
\end{tabular}

Table 8

Activation energy of the kinetic constants of the model.

\begin{tabular}{lcc}
\hline Constant & Intercept $\left(\mathrm{J} \mathrm{mol}^{-1} \mathrm{~K}^{-1}\right)$ & Slope $\left(\mathrm{J} \mathrm{mol}^{-1}\right)$ \\
\hline$k_{\mathrm{e}}$ & 47 & $-29,000$ \\
$k_{\mathrm{er}}$ & 110 & $-48,000$ \\
$k_{\mathrm{o}}$ & 150 & $-68,000$ \\
$k_{\mathrm{p}}$ & 160 & $-74,000$ \\
$k_{\mathrm{d}}$ & 110 & $-53,000$ \\
$k_{\mathrm{dcp}}$ & 110 & $-58,000$ \\
$k_{\mathrm{ro}}$ & 37 & $-20,000$ \\
$k_{\mathrm{rp}}$ & 43 & $-27,000$ \\
\hline
\end{tabular}

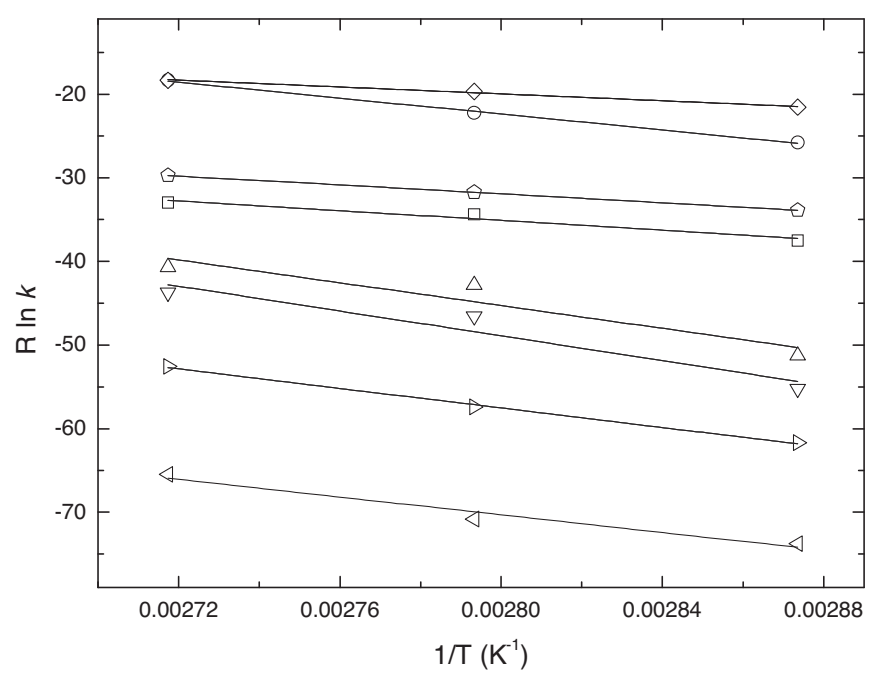

Fig. 14. Arrhenius plot between $348 \mathrm{~K}$ and $368 \mathrm{~K}$ of the kinetics constants calculated by the fitting results of the proposed kinetic model.

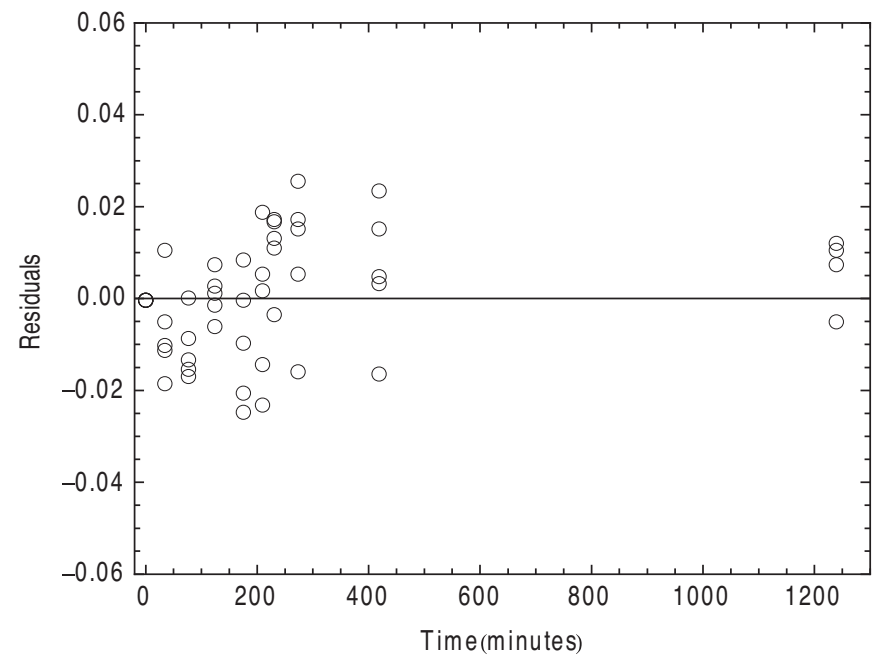

Fig. 15. Time sequence plot of the fitting residuals for a typical reactions kinetics. observing that the ratio $k_{\mathrm{ro}} / k_{\mathrm{rp}} \approx 4$ while $k_{\mathrm{o}} / k_{\mathrm{p}} \approx 2$ (Tables 6 and 7 ) $[14,15]$.

In Tables 6 and 7 the results of the fitting with Amberlyst 15 as catalyst and at different operation conditions are reported. The evaluation of the model by fitting the experimental data shows that all the parameters are consistent. In fact, the kinetic constants remain practically unaffected by varying reagent concentration (Table 6); as expected, their values rise as temperature increases. The cumulative Arrhenius plot for all the kinetic constants of the model are reported in Fig. 14 and their numerical values are in Table 8. Even though, the model allows a comprehensive explanation of all the aspects of the reaction, its complexity would require a much larger number of experiments in order to have numerical values with statistical meaning for each kinetic constant and the respective activation energy. In any case, in order to take the measure of the goodness of the model the time sequence plots of the residuals are studied. For instance, it can be seen in Fig. 15 that the residuals plot of a typical kinetics are well behaved around zero suggesting a good reliability of the model [33].

\section{Conclusions}

We tested commercial and modified macroreticular sulfonic styrene divinylbenzene resins (Amberlyst ${ }^{\mathrm{TM}} 15$ and Amberlyst ${ }^{\mathrm{TM}}$ 36 ) in the cyclohexylation of phenol. The modification of these materials by nitration and sulfonation allowed obtaining new catalysts with activities higher than the commercial materials. The reaction showed a complex kinetic path, which is characterized by the formation of the cyclohexyl phenyl ether as an equilibrium intermediate. The influence of the reagents on the initial reaction rate shows a zero reaction order for cyclohexene and $3 / 2$ for phenol. In addition, adsorption equilibrium of phenol on the resin is strong while cyclohexene is faintly adsorbed in the absence of phenol. Also cyclohexyl phenyl ether is poorly adsorbed on the resins. Furthermore, the adsorption of cyclohexene on pre-adsorbed phenol is almost strong as phenol adsorption. Starting from these evidences an Eley-Rideal mechanism is proposed where a surface complex sulfonic group-phenol-cyclohexene reacts with phenol in solution to give both the ether and the products of ring alkylation. The rearrangement of the ether and its decomposition are, instead, catalyzed by the free acid sites. Parallel independent reaction path is proposed for cyclohexene dimerization. The model satisfactorily fits the data giving a comprehensive explanation of the different aspects of the reaction.

\section{Notations}

$\mathrm{P} \quad$ phenol concentration $\left(\mathrm{mol} \mathrm{L}^{-1}\right)$

C cyclohexene concentration $\left(\mathrm{mol} \mathrm{L}^{-1}\right)$

$\mathrm{H} \quad$ free $\mathrm{H}^{+}$concentration $\left(\mathrm{mol} \mathrm{L}^{-1}\right)$

$\mathrm{P}_{0} \quad$ initial phenol concentration $\left(\mathrm{mol} \mathrm{L}^{-1}\right)$

$\mathrm{C}_{0} \quad$ initial cyclohexene concentration $\left(\mathrm{mol} \mathrm{L}^{-1}\right)$

$\mathrm{H}_{\mathrm{t}} \quad$ total $\mathrm{H}^{+}$concentration $\left(\mathrm{mol} \mathrm{L}^{-1}\right)$

oCP 2-cyclohexyl phenol concentration $\left(\mathrm{mol} \mathrm{L}^{-1}\right)$

pCP 4-cyclohexyl phenol concentration $\left(\mathrm{mol} \mathrm{L}^{-1}\right)$

CPE cyclohexylphenyl ether $\left(\mathrm{mol} \mathrm{L}^{-1}\right)$

HP concentration of adsorbed phenol ( $\left.\mathrm{mol} \mathrm{L}^{-1}\right)$;

HPC concentration of the surface complex phenol cyclohexene $\left(\mathrm{mol} \mathrm{L}^{-1}\right)$ 
dcp di-cyclohexylphenols concentration $\left(\mathrm{mol} \mathrm{L}^{-1}\right)$

cYcY cyclohexylcyclohexene concentration $\left(\mathrm{mol} \mathrm{L}^{-1}\right)$

$K_{\text {eq }} \quad$ constant of etherification equilibrium $\left(\mathrm{L} \mathrm{mol}^{-1}\right)$

$K_{\mathrm{HP}} \quad$ phenol adsorption equilibrium constant $\left(\mathrm{L} \mathrm{mol}^{-1}\right)$

$K_{\mathrm{HPC}} \quad$ adsorption equilibrium constant of cyclohexene on preadsorbed phenol $\left(\mathrm{L} \mathrm{mol}^{-1}\right)$

$k_{\mathrm{e}} \quad$ kinetic constant of ether formation $\left(\mathrm{L} \mathrm{mol}^{-1} \mathrm{~s}^{-1}\right)$

$k_{\mathrm{er}} \quad$ kinetic constant of ether destruction $\left(\mathrm{L} \mathrm{mol}^{-1} \mathrm{~s}^{-1}\right)$

$k_{0} \quad$ kinetic constant of 2-cyclohexylphenol formation $\left(\mathrm{L} \mathrm{mol}^{-1} \mathrm{~s}^{-1}\right)$

$k_{\mathrm{p}} \quad$ kinetic constant of 4-cyclohexylphenol formation $\left(\mathrm{L} \mathrm{mol}^{-1} \mathrm{~s}^{-1}\right)$

$k_{\text {ro }} \quad$ kinetic constant of ether rearrangement to 2cyclohexylphenol formation $\left(\mathrm{L} \mathrm{mol}^{-1} \mathrm{~s}^{-1}\right)$

$k_{\text {rp }} \quad$ kinetic constant of ether rearrangement to 4cyclohexylphenol formation $\left(\mathrm{L} \mathrm{mol}^{-1} \mathrm{~s}^{-1}\right.$ )

$k_{\mathrm{d}} \quad$ kinetic constant of cyclohexene dimerization $\left(\mathrm{s}^{-1}\right)$

$k_{\mathrm{dcp}} \quad$ kinetic constant of dicylohexylation product formation $\left(\mathrm{L} \mathrm{mol}^{-1} \mathrm{~s}^{-1}\right)$

$\varepsilon_{\mathrm{e}} \quad$ calculated error of $k_{\mathrm{e}}$ kinetic constant

$\varepsilon_{\mathrm{er}} \quad$ calculated error of $k_{\mathrm{er}}$ kinetic constant

$\varepsilon_{0} \quad$ calculated error of $k_{\mathrm{o}}$ kinetic constant

$\varepsilon_{\mathrm{p}} \quad$ calculated error of $k_{\mathrm{p}}$ kinetic constant

$\varepsilon_{\mathrm{dcp}} \quad$ calculated error of $k_{\mathrm{dcp}}$ kinetic constant

$\varepsilon_{\mathrm{d}} \quad$ calculated error of $k_{\mathrm{d}}$ kinetic constant

$\varepsilon_{\text {ro }} \quad$ calculated error of $k_{\text {ro }}$ kinetic constant

$\varepsilon_{\mathrm{rp}} \quad$ calculated error of $k_{\mathrm{rp}}$ kinetic constant

\section{Acknowledgements}

Financial support by Ca' Foscari University of Venice is gratefully acknowledged (Ateneo fund 2009). A thank to Dr. Davide Montin for some preliminary experiments carried out during his degree in Industrial Chemistry. Finally, a special thank to Mr. Claudio Tortato for the helpful discussions.

\section{Appendix A. Supplementary data}

Supplementary data associated with this article can be found, in the online version, at doi:10.1016/j.molcata.2011.11.025.

\section{References}

[1] H.U. Hammershaimb, T. Imai, G.J. Thompson, B.V. Vora, Kirk Ohtmer "Encyclopedia of Chemical Technology", vol. 2, Wiley, 2001.
[2] J.F. Lorenc, G. Lambeth, W. Scheffer, Kirk Ohtmer "Encyclopedia of Chemical Technology", vol. 2, Wiley, 2001.

[3] W. Keim, M. Röper, Ulmann's Encyclopedia of Industrial Chemistry, 6th ed., Wiley, 1998

[4] M.A. Harmer, Q. Sun, Appl. Catal. A: Gen. 221 (2001) 45-62.

[5] W.F. Hölderich, G. Heitmann, Catal. Today 38 (1997) 227-233.

[6] A. Mitsutani, Catal. Today 73 (2002) 57-63.

[7] M.M. Sharma, React. Funct. Polym. 26 (1995) 3-23.

[8] H. Zhang, S.M. Mahajani, M.M. Sharma, T. Sridhar, Chem. Eng. Sci. 57 (2002) 315-322.

[9] P.F. Siril, H.E. Cross, D.R. Brown, J. Mol. Catal. A: Chem. 279 (2008) 63-68.

[10] R.A. Rajadhyaksha, D.D. Chaudhari, Ind. Eng. Chem. Res. 26 (1987) 1276-1280.

[11] A. de Klerk, R.J.J. Nel, Ind. Eng. Chem. Res. 46 (2007) 7066-7072.

[12] R. Amandi, K. Scovell, P. Licence, T.J. Lotz, M. Poliakoff, Green Chem. 9 (2007) 797-801.

[13] N.I. Shuikin, E.A. Viktorova, Russ. Chem. Rev. 29 (1960) 560-570.

[14] K. Schofield, Aromatic Nitration, Cambridge University Press, Cambridge, 1980.

[15] P.B.D. De La Mare, J.H. Ridd, Aromatic Substitution, Butterworths Scientific Publications, London, 1959.

[16] B. Chaudhuri, M.M. Sharma, Ind. Eng. Chem. Res. 30 (1991) 227-231.

[17] E. Modrogan, M.H. Valkenberg, W.F. Hölderich, J. Catal. 76 (2009) 177-187.

[18] G.D. Yadav, P. Kumar, Appl. Catal. A: Gen. 286 (2005) 61-70.

[19] R. Anand, K.U. Gore, B.S. Rao, Catal. Lett. 81 (2002) 33-41.

[20] K. Wilson, D.J. Adams, G. Rothenberg, J.H. Clark, J. Mol. Catal. A: Chem. 159 (2000) 309-314.

[21] G.D. Yadav, G.S. Pathre, Ind. Eng. Chem. Res. 46 (2007) 3119-3127.

[22] G.D. Yadav, G.S. Pathre, J. Mol. Catal. A: Chem. 243 (2006) 77-84.

[23] J.F. Izquierdo, F. Cunill, M. Vila, M. Jhorra, J. Tejero, Ind. Eng. Chem. Res. 33 (1994) 2830-2835.

[24] L. Ronchin, L. Toniolo, A. Vavasori, J. Mol. Catal. A (2011).

[25] Q. Ma, D. Chakraborty, F. Faglioni, R.P. Muller, W.A. Goddard, T. Harris, C. Campbell, Y. Tang, J. Phys. Chem. A 110 (2006) 2246-2252.

[26] B. Bjoerkqvist, H. Toivonen, J. Chromatogr. 178 (1979) 271-276.

[27] S.J. Greg, K.S.W. Sing, Adsorption Surface Area and Porosity, 2nd ed., Academic Press, 1982.

[28] G.W. Roberts, in: P.N. Rylander, H. Greenfield (Eds.), Catalysis in Organic Synthesis, Academic Press, 1976, pp. 1-44.

[29] P.A. Ramachadran, R.V. Chaudhari, Three-Phase Catalytic Reactors, Gordon and Breach Sciences Publisher, 1982.

[30] M. Rae, M.N. Berberan-Santos, Chem. Phys. 280 (2002) 283-293.

[31] J.J. Kipling, Adsorption of Solution of Non Electrolytes, Academic Press, London, 1965 , p. 25

[32] G. Quartarone, L. Ronchin, C. Tortato, A. Vavasori, Int. J. Chem. Kinet. 41 (2008) 107-112.

[33] D.M. Bates, D.G. Watts, Nonlinear Regression Analysis \& Its Applications, Wiley New York, 1988.

[34] M. West-Nielsen, P.M. Dominiak, K. Wozniak, P. Erik Hansen, J. Mol. Struct. 789 (2006) 81-91.

[35] G. Ritzhaupt, J.P. Devlin, J. Phys. Chem. 95 (1991) 90-95.

[36] J.B. But, Reaction Kinetics and Reactor Design, 2nd ed., Marcel Dekker Inc., NY, 2000, p. 169.

[37] M. Vila, F. Cunill, J.F. Izquierdo, J.T.M. Iborra, Chem. Eng. Commun. 124 (1993) 223-232.

[38] G.A. Olah, A.M. White, D.H. O’Brien, Chem. Rev. 70 (1970) 561-591.

[39] G.A. Olah, G.K. Surya Prakash, J. Sommer, Superacids, J. Wiley, 1985, p. 90.

[40] http://reference.wolfram.com/mathematica/tutorial/NDSolveIntroductory TutorialDAEs.html. 